\title{
Evaluation of the TRMM 3B42 precipitation product using a high-density rain gauge network over complex terrain in north-eastern Iberia
}

1. Water Desalination and Reuse Center, Division of Biological and Environmental Sciences and Engineering, King Abdullah University of Science and Technology, Thuwal, Saudi Arabia.

2. Instituto Pirenaico de Ecología- CSIC, Campus de Aula Dei, P.O. Box 13034, Zaragoza, 50059, Spain.

3. Department of Geography, Mansoura University, Mansoura, Egypt.

E-mail: (kenawy@mans.edu.eg)

\section{Abstract}

The performance of the Tropical Rainfall Measuring Mission (TRMM) version 3B42 V7 product is validated over north-eastern Iberia, a region with considerable topographical gradients and complexity. Precipitation characteristics from a dense network of 656 rain gauges, spanning the period from 1998 to 2009, are used to evaluate the TRMM 3B42 estimates on a daily scale. A set of accuracy estimators, including the relative bias, mean absolute error (MAE), root mean square error (RMSE) and Spearman rho coefficient were used to evaluate the results. The assessment indicates that the TRMM 3B42 product is capable of describing the seasonal characteristics of the observed precipitation over most of the study domain. In particular, TRMM 3B42 precipitation agrees well with in situ measurements, with MAE less than 2.5 mm.day ${ }^{-1}$, RMSE of $6.4 \mathrm{~mm}^{- \text {day }^{-1}}$ and rho correlation coefficients generally above 0.6. TRMM 3B42 provides improved accuracies in winter and summer, whereas it performs much worse in spring and autumn. Spatially, the retrieval errors show a consistent trend, with a general overestimation in regions of low altitude and underestimation in regions of heterogeneous terrain. The TRMM 3B42 generally performs well over inland areas, while showing less skill in the coastal regions. A set of skill metrics, including a false alarm ratio [FAR], frequency bias index [FBI], the probability of detection [POD] and threat score [TS], are also used to evaluate TRMM performance under different precipitation thresholds $\left(1,5,10,25\right.$ and 50 mm.day $\left.{ }^{-1}\right)$. The results suggest that the TRMM 3B42 retrievals perform well in specifying moderate rain events (5-25 mm.day $\left.{ }^{-1}\right)$, but shows noticeably less skill in producing both light $\left(<1 \mathrm{~mm}\right.$.day $\left.{ }^{-1}\right)$ and heavy 


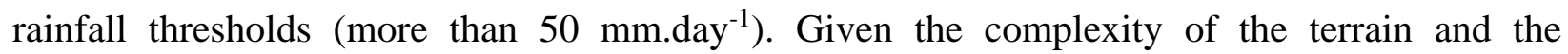
associated high spatial variability of precipitation in north-eastern Iberia, the results reveal that TRMM 3B42 data provide an informative addition to the spatial and temporal coverage of rain gauges in the domain, offering insights into characteristics of average precipitation and their spatial patterns. However, the satellite-based precipitation data should be used cautiously for monitoring extreme precipitation events, particularly over complex terrain. An improvement in precipitation algorithms is still needed to more accurately reproduce high precipitation events in areas of heterogeneous topography over this region.

Key words: precipitation; rain gauges; TRMM 3B42; evaluation; Iberia.

\section{Introduction}

Accurate measurement of precipitation over both space and time is crucial to better characterize and understand water and energy cycles (Lorenz and Kunstmann, 2012), to enhance understanding of climate regimes and their associated dynamics (Scarsoglio et al., 2013) and to improve hydro-meteorological forecasting (e.g., drought and flood) (Su et al. 2008). Though providing the principal source to describe precipitation characteristics, the performance of ground-based precipitation estimates is very sensitive to the spatial density of rain gauges, terrain complexity, the quality of data and the completeness and length of meteorological records (Groisman and Legates, 1994). Apart from providing basic meteorological forcing for diverse hydrological applications, assessing the potential impacts of global warming on the regional scale requires accurate data at fine spatial and temporal resolutions. However, this kind of assessment is challenging in areas of heterogeneous terrain, not only due to the high spatial and temporal variability of precipitation in these regions, but also as a consequence of the lack of a spatially dense network of rain gauges that can reliably capture the impacts of topographical gradients on local and regional climate (Lopez-Moreno et al., 2008; Evans and McCabe, 2013).

Over the last three decades, many attempts have been made to improve precipitation retrievals from satellites through merging various data sources, such as radar, microwave and thermal infrared remote sensing, allowing for a significant improvement in the accuracy, consistency and coverage of the retrievals (Behrangi et al., 2011). Currently, many sources of conventional 
remotely sensed precipitation estimates are available at high spatial $\left(0.25^{\circ}\right.$ or finer $)$ and temporal (3 hourly or shorter) resolutions, including (among others): the Precipitation Estimation from Remotely Sensed Information Using Artificial Neural Networks (PERSIANN) (Sorooshian et al. 2000), the Climate Prediction Center (CPC) Morphing algorithm (CMORPH) (Joyce et al. 2004), the Tropical Rainfall Measuring Mission (TRMM) Multi-satellite Precipitation Analysis (TMPA) (Huffman et al. 2007) and Multisensor Precipitation Estimation (MPE) (Seo et al., 1999). However, given that satellite-based estimates rely primarily on the interpretation of emitted or scattered radiation received by the satellite instruments, these estimates are accompanied by a host of uncertainties. Such uncertainties can originate from different sources, including sampling frequency, attenuation correction, attenuation-reflectivity relationships, partial beam filling and surface clutter rejection (Ebert et al., 2007). Levizzani et al. (2007) provide a detailed review of the errors associated with satellite precipitation retrievals.

Recently, a number of studies have been undertaken to assess the uncertainty associated with remotely sensed precipitation products across varying regions worldwide, including the continental United States (Chen et al., 2013), Europe (Stampoulis and Anagnostou, 2012), the Mediterranean basin (Feidas et al., 2009), Southern America (Vila et al., 2009), China (Yu et al., 2009), India (Prakash et al., 2014), West Africa (Jobard et al., 2011), the Indian Ocean (Prakash and Gairola, 2014) and the Pacific Ocean (Sapiano and Arkin, 2009). These works have compared satellite-based precipitation products either using other satellite-based sources (e.g., Masunaga et al., 2002; Islam et al., 2012) or surface observations (e.g., Adeyewa and Nakamura, 2003; Prakash and Gairola, 2014). For example, Masunaga et al. (2002) compared precipitation estimates from various TRMM Microwave Image (TMI) products over the tropics, suggesting that the disagreement between these products was a consequence of their different physical basis. More recently, Lockhoff et al. (2014) conducted a comparison between the daily precipitation data from the Global Precipitation Climatology Project (GPCP) and the European Daily Highresolution Observational Gridded Dataset (E-OBS), suggesting a good agreement of climatologies (e.g., mean, frequency and intensity) and empirical frequency distributions. Similarly, Kidd et al. (2012) compared high-resolution precipitation products with radar and rain gauge observations in northwestern Europe. Also, Adeyewa and Nakamura (2003) compared rainfall estimations from the TRMM precipitation radar (PR), TRMM 3B43 and Global Precipitation Climatology Project (GPCP) satellite products over Africa, concluding that the TRMM 3B43 matches well with rainfall observations. Over the eastern Mediterranean, Feidas et 
al. (2009) found good agreement between TRMM estimations and gauge measurement data on a

97

98

99

100

101

102

103

104

105

106

107

108

109

110

111

112

113

114

115

116

117

118

119

120

121

122

123

124

125

126

127

seasonal time scale, with the best results found during autumn, summer and spring.

TRMM products, which are available since early 1998, are one of the major sources of satellite retrieved precipitation, providing spatially homogeneous observations with good spatial coverage and few missing values (Huffman et al. 2007). The main advantage of the TRMM $3 B 42$ retrievals is that they incorporate multiple-sensor and multi-satellite data, in addition to in-situ based observations, allowing for more accurate and reliable precipitation estimates (Huffman and Bolvin, 2012). With the merits of multi-sensors calibration, quasi-global coverage, high spatial and temporal resolutions and low latency in availability, several studies have found TRMM to be superior to other available satellite-based products (see for example, Adeyewa and Nakamura, 2003; Ebert et al., 2007; Huffman et al., 2007). To develop a consistent and robust global product, validation of satellite-based precipitation products is required over diverse regions and seasons to define and improve the quality of measurements and to accurately reveal climatological features. Over the Iberian Peninsula, relatively little work has been done to assess the accuracy of the TRMM products or to use these data for meteorological studies. In their assessment of the accuracy of satellite precipitation products over the Unites States, Europe and Australia, Ebert et al. (2007) found that the performance of a single product can significantly differ from one region to another. Therefore, validating TRMM products on a regional basis over the Iberian Peninsula is required to ensure confidence in product estimates.

In this work, we focus on assessing the performance of the recent version of the TRMM precipitation product (3B42 V7) in north-eastern Iberia. From many perspectives, the northeastern region of the Iberian Peninsula offers a unique setting to assess the capabilities of TRMM at high spatial detail. First, the network of precipitation observatories in the region is one of the densest regional precipitation networks in the Iberian Peninsula, providing a representative areal means and allowing for a detailed and conventional assessment of precipitation products. Second, the region is characterized by complex terrain that exerts strong precipitation gradients, associated with different underlying microphysical and dynamical processes of climate. In addition, numerous studies have identified a wide range of large-scale drivers and rainfall phenomena associated with the high spatial-temporal variations of precipitation in the region, including orographic rain, convective processes and thunderstorm activities (e.g., Ramis et al., 1997; Beguería et al., 2009; Lopez-Moreno et al., 2010). Finally, the north-eastern Iberian 
Peninsula shows strong topographic gradients and large topographic diversity, containing mountains of more than $3400 \mathrm{~m}$, four different mountain chains, semiarid depressions as a consequence of topographic barriers and the influence of two seas: the Atlantic Ocean and the Mediterranean Sea (El Kenawy et al., 2013). In areas of complex topography like north-east Iberia, strong scattering signals are likely to occur, whose effects can differ markedly depending on exposure and altitude, especially over cold land surfaces and snow-covered areas. Previous studies have already identified the poor performance of TRMM precipitation products over regions with very complex topography, particularly in tropical and mid-latitude mountain systems, such as the Andes (Zulkafli et al., 2014), the Himalaya (Shrestha et al., 2012) and the Ethiopian plateau (Hirpa et al., 2010).

The major objective of this work is to assess the ability of the TRMM 3B42 (V7) precipitation product to accurately replicate precipitation variability and extremes using a dense and highquality rain gauge network in north-east Iberia. Considering the high spatial and temporal variability of precipitation in the region, such a comparison is useful not only for providing a better indication on the accuracy of the TRMM 3B42 across the whole domain, but also for improving their retrievals at this regional scale, offering a basis for better assessment of precipitation and related hydrological impacts across the region.

\section{Data and methods}

\subsection{Study area}

The study domain is located in northeast Iberia between latitudes $39^{\circ} 43^{\prime} \mathrm{N}$ and $43^{\circ} 29^{\prime} \mathrm{N}$ and longitudes $05^{\circ} 01^{\prime} \mathrm{W}$ and $03^{\circ} 17^{\prime} \mathrm{E}$. It covers an area of approximately $186.000 \mathrm{~km}^{2}$, which accounts for roughly 32\% of the total area of the Iberian Peninsula (Figure 1). The topography varies from mountains with a maximum elevation of $3400 \mathrm{~m}$ above mean sea level (the Pyrenees), to the alluvial plains in the lower reaches of the Ebro basin, which is the largest hydrological division in the peninsula. The study domain encompasses a large variety of climate zones, including semi-arid, Mediterranean, oceanic, continental and mountainous. These climate zone variations derive mostly from weather system interactions associated with atmospheric circulation, latitude, altitude, topography, vegetation cover and land-sea interactions (Capel, 2000). From a global perspective, the region encompasses a climatic gradient between midlatitude and subtropical regimes. It is also situated in a transitional zone where the Mediterranean 
configurations and the Atlantic influences interact with each other. The mean annual rainfall in the region typically exceeds $650 \mathrm{~mm}$ (Cuadrat et al., 2004), with maximum precipitation recorded during the period from October to May, which provides about $60 \%-80 \%$ of the annual precipitation, with two main peaks in October and April. Seasonally, summer and winter contribute to nearly $16.9 \%$ and $23.1 \%$ of the annually averaged accumulated precipitation, respectively, compared with $27.9 \%$ in spring and $32.1 \%$ in autumn. The Pyrenees and the most elevated sites in other mountainous regions are covered with snow during winter and early spring. A detailed summary of the climate of the study domain can be found in Font-Tullot (1983) and Capel (2000).

\subsection{Data sets}

\subsubsection{TRMM Precipitation dataset}

The TRMM was launched in 1997 as a collaborative project between the National Aeronautics and Space Administration (NASA) and the Japanese Aerospace Exploration Agency (JAXA) to monitor rainfall in the tropical area from $35^{\circ} \mathrm{S}$ to $35^{\circ} \mathrm{N}$, with a revisit time of one day on average (Huffman et al. 2007). Here, we consider the rain rate data from the TRMM $3 B 42$ product (V7), which was officially released in December 2012 to correct for defects present in the algorithms of earlier versions (V4 to V6) (Chen et al., 2013). The TRMM Microwave Image (TMI) land rainfall algorithm in the V7 products has several improvements over previous versions (Huffman and Bolvin, 2012). First, the relationship between rain rates and TMI 85-GHz brightness temperatures for convective and stratiform rain are generated using the combined TMI-PR data. Second, estimation of the ratio of convective rainfall to total rainfall significantly lowers the overestimation by TMI during the warm season. Third, TRMM V7 incorporates more observation datasets at different detection ranges, including the latest version of GPCC Full Analysis from 1998 to 2010, besides version 6 GPCC Monitoring Analysis. Finally, the TRMM V7 algorithm combines precipitation estimates from land surface rain gauge analyses, in addition to multiple satellite sensors and systems (e.g., TMI, Advanced Microwave Scanning Radiometer for Earth Observing Systems (AMSR-E), Special Sensor Microwave Imager (SSMI), Special Sensor Microwave Imager/Sounder (SSMIS), Advanced Microwave Sounding Unit (AMSU), Microwave Humidity Sounder (MHS) and microwave-adjusted merged geo-infrared (IR)) (Huffman and Bolvin, 2012). This combination makes the TRMM 3B42 V7 useful for 
191

192

193

194

195

196

197

198

199

200

201

202

203

204

205

206

207

208

209

210

211

212

213

214

215

216

217

218

219

220

221

222

223

diagnosing precipitation relative to previous versions, which relied on a single sensor precipitation estimate.

In this work, we used the daily version of the 3B42 precipitation product (in mm.day ${ }^{-1}$ ), which was aggregated from the 3-hourly product $\left(\mathrm{mm} \mathrm{hr}^{-1}\right)$ and sampled at a 0.25 -degree spatial resolution for a global belt extending from $50^{\circ} \mathrm{S}$ to $50^{\circ} \mathrm{N}$. Our analyses were restricted to the period of overlap with rain gauge data (1 January 1998 through 31 December 2009). Further information on the TRMM mission and instruments can be found in Kummerow et al. (2000). Particular details and aspects related to the 3B42 V7 product can also be found via http://trmm.gsfc.nasa.gov/3b42.html.

\subsubsection{Gauge data}

To evaluate the performance of the TRMM 3B42 precipitation estimations, we exploit a very dense network of rain gauges covering the period from January 1998 through December 2009. The network incorporates a total of 656 observatories, with an average station-to-station distance of $5 \mathrm{~km}$, making it ideally suited to evaluate the TRMM data. The raw daily precipitation data were provided by the Spanish Meteorological Agency (Agencia Estatal de Meteorologia, AEMT) and subjected to rigorous quality assessments and homogeneity testing. A complete description of the development of this data set can be found in Vicente-Serrano et al. (2010). Overall, the final data set features a complete data record (no missing values), free of anomalous data and inhomogeneities for the 12-year period. The spatial distribution of the rain gauge stations is shown in Figure 1.

The network exceeds most of the requirements for robust assessment of precipitation estimates from the TRMM product. The precipitation data set is very dense over large parts of the region, making it useful for a detailed assessment of TRMM performance and minimizing any uncertainty associated with inadequate sampling. The main climate zones in the region (e.g., semi-arid, maritime, continental and mountainous) are also well-represented by the current network. However, in some less accessible regions (e.g., the Pyrenees), TRMM data may be useful as a "proxy" to in situ measurements, given the lower spatial density of observations. This is a prime example of where TRMM precipitation estimates may be of benefit for filling in spatial gaps in ground-based data, providing information on the interconnections between climate and hydrology in these areas. 
To provide a detailed spatial assessment of the performance of TRMM 3B42, we divided the study domain into four main sub-regions (R1-R4). To achieve this classification, we first ranked all observatories according to their annual total precipitation. Then, the observatories were simply grouped according to their rank, so that R1 incorporated observatories whose average annual precipitation lies in the first quartile of the entire network (i.e., between Q1 and Q25), R2 the second quartile (Q25-Q50) and so on for R3 (Q50-Q75) and R4 (Q75-Q100). This regionalization will serve as the basis for assessing the spatial performance of TRMM 3B42 data. Figure 2-a illustrates the spatial distribution of the four sub-regions, which are distinct and meaningful from a climatic and geographical perspective. The four sub-regions also correspond to well-defined climate regimes following Capel (2000). According to the classification, R1 represents observatories with the least annual precipitation in the whole domain ( $<400 \mathrm{~mm}$. year $\left.^{-1}\right)$, whereas the largest annual records are accounted for in R4 (750-2300 mm. year $\left.{ }^{-1}\right)$. R2 and R3 include observatories with a median precipitation of about $400-750$ mm. year ${ }^{-1}$.

Figure 2-b clearly illustrates that the annual precipitation is strongly controlled by elevation, with the four sub-regions displaying their dependency on topography. R1 and R2 are generally situated in areas dominated by lower altitudes (average altitude $=469 \mathrm{~m}$ for R1 and $689 \mathrm{~m}$ for R2), with the vast majority of R1 contained within the Ebro basin. R3 is located at the foothills of the high mountainous regions in the north of the study domain, while R4 is mostly situated in areas of complex topography to the north (e.g., the Pyrenees), with elevations as high as 2000$3400 \mathrm{~m}$. However, R4 also stretches to the west, including coastal areas along the Cantabric Sea.

\subsection{Validation procedure}

There are different sources of uncertainty in precipitation estimates from satellite-based products.

The common sources of errors can generally be associated with data processing, discrete sampling, radiance measurements, retrieval algorithms and view of the sensors (Huffman et al., 1997). Therefore, rainfall estimates obtained from the satellites should be validated against rain gauge observations in order to ensure their reliability. Here, we validated the daily data for each rain gauge individually against the specific TRMM pixel that contains it. The validation using point-to-grid comparison was performed to limit the possible impacts of complex topography on the outputs of any interpolation algorithm. Moreover, the high spatiotemporal variability of precipitation within the study domain can further complicate the results of any interpolation 
256

257

258

259

260

261

262

263

$264 \quad r h o=\frac{6 \sum d_{i}^{2}}{N\left(N^{2}-1\right)}$
265

266

267

268

269

270

271

272

273

274

275

276

277

278 279

280

281

where $N$ is the number of observations, $O$ is the gauge-measured precipitation, $P$ is the TRMM-derived precipitation, $\bar{O}, \bar{P}$ are the mean of $\mathrm{O}$ and $\mathrm{P}$, respectively, $\mathrm{d}_{\mathrm{i}}$ is the difference between the ranks of corresponding values of precipitation, and $N$ is the number of values in the data set, and ${ }^{i}$ is the counter for individual observed and TRMM values.

The BIAS is an indicator of the sign of the prediction (i.e., overestimating/underestimating) and also the average difference between TRMM and observed values. In comparison, the MAE is a measure of how far the TRMM value is from the measured value, as it is simply calculated as the average of absolute difference errors. Generally, the TRMM product is considered perfect when the values of BIAS and MAE are close to zero. RMSE is related to the BIAS and the standard deviation of the differences between the records of the gauge and TRMM data, while the Spearman rho correlation coefficient is a measure of the temporal correlation between the two data sources. The validation statistics were calculated on a daily basis by comparing individual rain gauge data with TRMM rainfall estimates at specific grid boxes.

While information on changes in the mean precipitation is important to understand the long-term variability of precipitation, monitoring changes in heavy precipitation events are relevant to 
282

283

284

285

286

287

288

289

290

291

292

293

294

295

296

$297 \quad F B I=\frac{a+b}{a+c}$

$298 \quad F A R=\frac{b}{a+b}$

299

300

301

302

303

304

305

306

307

308

309

310 metrics, as:

$P O D=\frac{a}{a+c}$

$T S=\frac{a}{a+b+c}$

examining possible hydrological, economic and societal impacts of change and variability. In order to quantitatively examine the potential of TRMM 3B42 to reproduce the precipitation response at different ranges (thresholds), a set of categorical metrics were also calculated at a daily time step, including: the frequency bias index (FBI), false alarm ratio (FAR), probability of detection (POD) and threat score (TS) (Wilks, 1995). These statistics have been widely used in many works to measure the correspondence between the observed and estimated occurrence of rainy events using remotely sensed products (e.g., Su et al. 2008; Shrestha et al. 2012). Here, we defined six different categories (thresholds) that identify the capability of TRMM 3B42 to reproduce very light $\left(<1 \mathrm{~mm} \cdot\right.$ day $\left.^{-1}\right)$, light $\left(1-5 \mathrm{~mm}^{- \text {day }^{-1}}\right)$, slightly moderate $\left(5-10 \mathrm{~mm} \cdot \mathrm{day}^{-1}\right)$, moderate (10-25 mm.day $\left.{ }^{-1}\right)$, heavy rain (25-50 mm.day $\left.{ }^{-1}\right)$ and extremely heavy rain (>50 mm.day ${ }^{-1}$ ). For each daily precipitation threshold, we created a $2 \times 2$ contingency table (see Table I for an explanation of the structure of the $2 \times 2$ contingency table). Following the results of the contingency table for each precipitation threshold, we simply calculated the categorical

where $a$ is the number of hits (i.e., observed rain events correctly detected), $b$ is the number of false alarms (i.e., detectable rainfall events, but not observed), and $c$ refers to the number of misses (i.e., observed rain events not detected by the TRMM).

The FBI indicates whether the TRMM tends to underestimate $(\mathrm{FBI}<1)$ or overestimate $(\mathrm{FBI}>1)$ rain events, whereas the POD indicates the fraction of rain events that were correctly detected. The FAR considers all forecasts of rain, giving indication on the fraction of rain events that were incorrectly defined (i.e., TRMM overpasses registered concurrent rain, which did not occur in reality). The TS reveals the overall skill of the TRMM as it summarizes the ratio between the 
311

312

313

314

315

316

317

318

319

320

321

322

323

324

325

326

327

328

329

330

331

332

333

334

335

336

337

338

339

340

341

342

number of hits and the total number of hits, misses and false alarms. Overall, a perfect agreement between observations and TRMM data occurs when $\mathrm{FBI}=1, \mathrm{FAR}=0, \mathrm{POD}=1$ and $\mathrm{TS}=1$.

\section{Results}

\subsection{Validation results}

In this work, we used the \%BIAS, MAE, RMSE and Spearman rho coefficient as the standard statistical parameters to evaluate the performance of the TRMM 3B42 data across the study domain. The validation statistics were calculated by comparing rain gauge data with rainfall estimates at individual grid boxes on a daily scale. Figure 3 summarizes the results of the statistical indices averaged for each season. The seasons were defined as: winter (DecemberJanuary-February, DJF), spring (March-April-May, MAM), summer (June-July-August, JJA) and autumn (September-October-November, SON). As depicted, the TRMM 3B42 tends to overestimate the observed precipitation across the whole domain in most seasons. In particular, the \%BIAS ranged from $12.8 \%$ (winter) to $29.7 \%$ (spring), with an annual average on the order of $18.7 \%$. It should be noted that underestimation is a recurrent feature at the grid scale, with the TRMM 3B42 showing a negative bias in 40\% of the grid cells in winter, compared with $18.2 \%$ in spring, 30\% in autumn and 33.5\% in summer. Figure 3 also shows the seasonal variations of the \%BIAS for the four sub-regions. It is interesting to notice that the errors show a consistent trend, with a general overestimation in regions of low (R1) and moderate (R2 and R3) precipitation and underestimation in regions of higher precipitation (R4). In particular, the positive bias in R1 varied from $36.4 \%$ (winter) to $52.8 \%$ (spring), which is higher with respect to other regions. In contrast to all regions, a negative bias was apparent in R4, with a relative bias varying from $-7.8 \%$ (summer) to $-17.5 \%$ (winter) and almost near-to-zero values in spring.

Figure 3 also details that the MAE over the domain as a whole varied from $1.61 \mathrm{~mm}^{-d a y^{-1}}$ (summer) to $2.78 \mathrm{~mm}_{\text {.day }}{ }^{-1}$ (spring), with an annual error of $2.46 \mathrm{~mm}$.day ${ }^{-1}$. The best agreement was found in summer and winter, where the percent of grids showing MAE less than 2 mm.day ${ }^{-1}$ were 77.4 and $48.6 \%$, respectively. The least accurate results were shown in the most rainy seasons, with 78\% (spring) and $75.5 \%$ (autumn) of the grid boxes exceeding a daily error of 2 mm. Similar to the \%BIAS, the MAE errors showed a consistent trend, with the best results found in the least rainy regions (R1 and R2) and the poorest skill occurring in the heaviest rainfall region (R4). In R4, the MAE showed more variable performance, with values generally 
343

344

345

346

347

348

349

350

351

352

353

354

355

356

357

358

359

360

361

362

363

364

365

366

367

368

369

370

371

372

373

374

375

above 4 mm.day ${ }^{-1}$ across most of seasons, suggesting a strong systematic error of precipitation estimation at higher elevations. The RMSE showed a similar pattern to the \%BIAS and MAE, with the lowest errors $\left(4.75 \mathrm{~mm} \cdot \mathrm{day}^{-1}\right)$ found in summer and the maxima in spring (6.72 mm.day ${ }^{-}$ $\left.{ }^{1}\right)$ and autumn $\left(7.56\right.$ mm.day $\left.{ }^{-1}\right)$.

The Spearman rho correlation coefficients between TRMM 3B42 and rain gauge data for each season are also shown in Figure 3 and Table II. The seasonal values of rho coefficient were generally above 0.6 for all regions and most seasons, which is statistically significant at the $99 \%$ confidence level. In accordance with MAE and RMSE, the highest values of rho were found in the regions with lowest rainfall (R1and R2), compared with regions of higher rainfall (R3 and R4). As summarized in Table II, the highest values of rho occurred in R1 during summer (0.73), autumn (0.72) and winter (0.71). In contrast, the lowest correlation values were ascribed to R4, with values of 0.46 and 0.47 during spring and winter, respectively. As many climatic applications (e.g., precipitation and drought impact assessments) are more relevant to monthly and seasonal scales of climate data rather than daily scales, we provided a detailed evaluation of the temporal agreement between the TRMM 342 and in-situ data by calculating the rho coefficient on a monthly scale. Figure 4 suggests significant month-to-month variations of rho coefficients, with the highest values found in the period from June to September (0.68-0.72), and the lowest values in April (0.57), January and May (0.59). The rho coefficients were found more promising for R1 and R2 than for R3 and R4.

The spatial distribution of the \%BIAS was also examined and compared for all seasons, with results illustrated in Figure 5. For each season, the distribution of the \%BIAS is quite homogeneous, with a clear contrast between the mainland (overestimation) and the coasts (underestimation). This contrast is particularly evident in winter and summer. A considerable overestimation in the central areas of the Ebro valley was also observed, particularly in spring and summer. Interestingly, all areas close to water bodies showed a negative bias for all seasons. For example, the \%BIAS along the Cantabric Sea varied from $-10 \%$ to $-50 \%$ during winter, which is equivalent to -1.0 to $-2.4 \mathrm{~mm}$. day $^{-1}$. The Mediterranean region also exhibited a negative bias in winter, but weaker than that of the Cantabric Sea (roughly 0 to $-20 \%$; or 0 to -0.4 mm.day ${ }^{-1}$ ). Another interesting feature was found over the Pyrenees during springtime, where precipitation values were markedly overestimated (50-70\%; 1.2-1.6 mm.day ${ }^{-1}$ ), implying that the TRMM 3B42 performs poorly in the Pyrenees during spring. 
377 Figure 6 illustrates the spatial distribution of the RMSE (mm.day ${ }^{-1}$ ) for each season. Similar to the \%BIAS, the TRMM 3B42 presents larger errors near to the coasts, particularly the Cantabric Sea, with values ranging between 8 and 15 mm.day $^{-1}$. The lowest errors were observed in the central areas of the Ebro basin, with a clear south-north gradient and values ranging between 0-6 mm.day ${ }^{-1}$. Lower RMSEs (0-2 mm.day ${ }^{-1}$ ) were observed in summer, where the highest RMSE values ( $>7 \mathrm{~mm}^{-\mathrm{day}^{-1}}$ ) were restricted to a small number of grids in the northern parts of the study domain.

\subsection{Spatial and temporal distribution of precipitation}

386 In Figure 7, the mean seasonal precipitation from rain gauges is plotted against precipitation estimates from the TRMM 3B42 for the period from January 1998 to December 2009. The results reveal that seasonal precipitation sums provided by rain gauges were fairly well estimated by the TRMM 3B42. The best agreement was found in winter and autumn $(r=0.84)$, whereas the poorest agreement occurred during spring $(\mathrm{r}=0.73)$. On average, the maximum departure between the seasonal cumulative rain gauge and TRMM 3B42 estimates was found during spring (19.4\%), compared with 6.8\% in winter, $7.1 \%$ in summer and $7.4 \%$ in autumn. The areal average annual rainfall measured by the TRMM $3 B 42$ is $685.2 \mathrm{~mm}$, which differs from the rain gauge data by 9.2\%. As depicted, a general underestimation of annual sums was noted at sites with annual precipitation above $1000 \mathrm{~mm}$, while overestimation was more evident for those locations

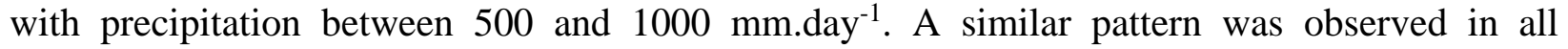
seasons, but particularly in winter. This finding demonstrates the ability of the TRMM 3B42 to reproduce precipitation totals at observatories with lower precipitation than at those with moderate and higher precipitation: at least in this study region. The pattern was also confirmed for seasonally accumulated precipitation, as depicted in Figure 8. The number of rain gauges with high-order accumulated precipitation is markedly lower than those of corresponding TRMM 3B42 pixels. This finding is confirmed for winter and autumn that are opposite to spring 404

Figure 9 illustrates the monthly regimes of accumulated precipitation estimated from the TRMM 3B42 and rain gauge data. It can be seen that TRMM 3B42 precipitation data closely follow the observed annual cycle of area-averaged precipitation, with a clear bi-model response. In particular, two peaks were observed in all regions, with the first occurring in late spring (April- 
May) and the second in early autumn (September-October). In contrast, the minima typically corresponded to February and the summer months (June-August). At the regional scale, the best agreement was found for R1 ( $\mathrm{r}=0.97)$, while the worst performance occurred in $\mathrm{R} 4$ ( $\mathrm{r}=0.85$ ). Previous investigations across the study domain showed that precipitation in the region is concentrated in the period from October to May, with double peaks occurring in April and October (e.g., Vicente-Serrano and Lopez-Moreno, 2006), which fits well with the patterns derived from the TRMM 3B42 precipitation product.

\subsection{Performance of TRMM $3 B 42$ at different daily precipitation thresholds}

To examine the performance of the TRMM 3B42 product in reproducing the frequency of precipitation occurrence events at or above a particular precipitation threshold, a set of statistical skill scores (FBI, FAR, POD and TS) was computed. Figure 10 depicts the results of FAR, FBI, POD and TS scores for the domain and its sub-regions at different daily precipitation ranges. Overall, FBI values inform that TRMM 3B42 captured slightly moderate (5-10 mm.day ${ }^{-1}$ ) and moderate precipitation $\left(10-25 \mathrm{~mm}^{- \text {day }^{-1}}\right)$ better than it did very light $\left(<1 \mathrm{~mm}\right.$. day $\left.^{-1}\right)$ and very heavy precipitation $\left(>50 \mathrm{~mm} \cdot \mathrm{day}^{-1}\right)$. The product poorly reproduced the occurrence of days with very light rain $(<1 \mathrm{~mm})$ in all regions and throughout the year, with a considerable overestimation in winter and autumn. TRMM 3B42 also tends to overestimate the frequency of light rain events in the range 1-5 mm.day ${ }^{-1}$ during winter and autumn, while it underestimated these in spring and summer. The results also suggest that there was a systematic underestimation of slightly moderate and moderate precipitation occurrence (5-25 mm.day $\left.{ }^{-1}\right)$ in all seasons and regions. Interestingly, the occurrence of very heavy events $\left(>50 \mathrm{~mm} \cdot\right.$ day $\left.^{-1}\right)$ were markedly overpredicted during the warm seasons (summer and autumn), whereas they were under-predicted in the cold seasons (winter and spring). Spatially, R4 showed less predictability of precipitation occurrence at all thresholds, compared with other regions. For example, the FBI values corresponding to the threshold higher than $50 \mathrm{~mm}^{- \text {day }^{-1}}$ in R4 were 2.2 in summer and 2.1 in autumn, which are far from the ideal value of 1 .

Figure 10 also presents variations of FAR values as a function of the precipitation threshold. FAR values showed a V-shaped trend, with the worst performance found for light and heavy rain thresholds. In contrast, TRMM 3B42 performed well for the occurrence of moderate rainfall events in the range 5-25 mm.day ${ }^{-1}$, with values close to 0.6. The sharp increase in FAR values for thresholds below 1 mm.day ${ }^{-1}$ and above $50 \mathrm{~mm}^{\text {day }}{ }^{-1}$ suggests that TRMM 3B42 was less 
442

443

444

445

446

447

448

449

450

451

452

453

454

455

456

457

458

459

460

461

462

463

464

465

466

467

468

469

470

471

472

473

474

skillful in correctly capturing the frequency and magnitude of light and heavy rain events. This response was evident for all seasons, with some significant regional differences, where TRMM 3B42 showed the best performance for R1 and the worst for R4. Similar to the FAR, the POD and TS values indicate that the performance of the TRMM 3B42 consistently degrades for lower and upper precipitation thresholds. The distribution of PODs shows that the fraction of precipitation occurrences during very light rain days $\left(<1 \mathrm{~mm}\right.$.day $\left.{ }^{-1}\right)$ was inadequately detected, with values close to zero in most seasons. The four regions also had an equivalent performance, with the lowest POD and TS scores for the precipitation thresholds up to $1 \mathrm{~mm}$.day ${ }^{-1}$. On the contrary, the values rapidly increased for the moderate thresholds, indicating a significant improvement in TRMM 3B42 detection skills. Again, the values dropped sharply for heavy and very heavy rain events, with values near to 0 (no skill).

Overall, the detectability of the TRMM 3B42 for precipitation occurrence and precipitation amount was generally reasonable. The TRMM 3B42 can correctly identify the moderate rain events (low FAR and high POD and FAR), but fails to capture the light and intense rain events (high FAR and low POD and FAR). This finding is important from a hydrological perspective, as high rainfall ranges $\left(>25 \mathrm{~mm}_{\text {.day }}{ }^{-1}\right)$ significantly contribute to the total precipitation and can thus have severe natural and socioeconomic impacts on both the physical and human environments (e.g., flooding, soil erosion, human mortalities and crop losses).

Figure 11 illustrates the fraction of days corresponding to each precipitation threshold, as derived from the TRMM 3B42 compared to rain gauge data. As illustrated, the non-rainy days had the largest occurrence year round in both TRMM 3B42 and ground measurements, with the fraction of non-rainy days well captured by the TRMM 3B42 product. On average, the non-rainy days accounted for as much as $76.2 \%$ of the total days in rain gauge data, compared with $76.4 \%$ in the TRMM 3B42 estimates. However, the TRMM 3B42 tended to underestimate the fraction of dry days in the least rainy region (R1), while it overestimated those in the rainiest region (R4). In R4, non-rainy days occurred over $69.7 \%$ of days per year, as suggested by the TRMM 3B42, compared with $64.1 \%$ of days in the observed data. The occurrence of precipitation ranges higher than $5 \mathrm{~mm}^{- \text {day }^{-1}}$ in the TRMM 3B42 was higher than those from rain gauges in all regions. Again, the only exception corresponded to R4, which exhibited underestimation in the 5-10 and 10-25 mm.day ${ }^{-1}$ thresholds. As illustrated in Figure 11, both the rain gauge and TRMM 3B42 estimates suggest the precipitation threshold $\left(1-5 \mathrm{~mm}^{\left.-d_{a y}{ }^{-1}\right)}\right.$ as the most frequent among all 
475

476

477

478

479

480

481

482

483

484

485

486

487

488

489

490

491

492

493

494

495

496

497

498

499

500

501

502

503

504

505

506

precipitation ranges, contributing to $8.4 \%$ and $9.5 \%$ of the total days, respectively. As expected,

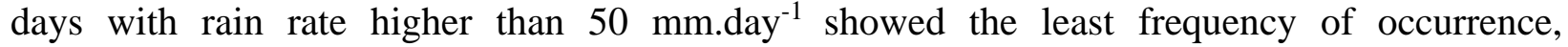
contributing to only $0.19 \%$ (gauge) and $0.18 \%$ (TRMM 3B42) of the total days.

Figure 12 summarizes the relative contribution of each precipitation range to the annual accumulated precipitation using TRMM 3B42 and observed data. Interestingly, in contrast to the regional differences defined for the occurrence of rain events in Figure 11, TRMM $3 B 42$ tended to underestimate the contribution of light rain events, whereas it overestimated the contribution of moderate and high rain thresholds. More specifically, for all precipitation ranges below 10 mm.day ${ }^{-1}$, TRMM 3B42 underestimated their relative contribution to the annual accumulated precipitation, compared with ground measurements. One representative example is the days with rain rate of 1-5 mm.day ${ }^{-1}$, whose frequency of occurrence was generally higher for TRMM 3B42 than for the rain gauge (Figure 11). In contrast, the relative contribution of these days to the total precipitation amounts was markedly under-predicted by TRMM 3B42, with significant and systematic differences between the four regions. This picture is reversed for the precipitation ranges between 10 and 50 mm.day ${ }^{-1}$ (i.e., moderate and high events), with an overestimation of their contribution to the annual total in all regions than in observations. This systematic

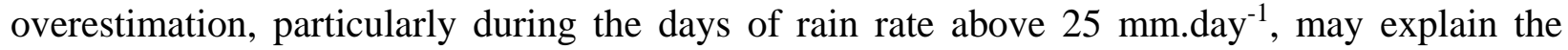
warm bias found in the study domain in most seasons. As illustrated in Figure 12, days with precipitation range below $1 \mathrm{~mm}$ contributed to approximately $0.8-1.5 \%$ of the total observed precipitation, which compared well with TRMM 3B42 (0.7-1.5\%). Over higher rainfall regions (R3 and R4), the contribution of light rain to total precipitation was meaningless (less than 0.5\%). In the same context, around 37.8\% (gauge) and 38.2\% (TRMM 3B42) of the precipitation amounts were allocated to days with rain intensity of 10-25 mm.day ${ }^{-1}$. Although the high rainfall range (>50 mm.day ${ }^{-1}$ ) had a very small frequency, with average of occurrence less than $0.5 \%$ of the total days for both TRMM 3B42 and rain gauge (Figure 11), their contributions to the total rainfall were as high as $4-8 \%$ for both.

\section{Discussion}

This study provides a detailed evaluation of the performance of TRMM 3B42 (V7) precipitation estimates through comparison with observations derived from a dense network of rain gauges (656 stations) over NE Iberia. Based on 12 years (1998-2009) of data, the performance of the 
TRMM 3B42 was assessed by directly comparing rain gauge and TRMM 3B42 data using a set of accuracy statistics, including the BIAS, MAE, RMSE and Spearman rho correlation.

\subsection{Seasonal variations}

Examining the statistical results of the accuracy indicators and their seasonal differences indicates that the skill of the TRMM 3B42 estimates is seasonally dependent, with better performance observed in summer and winter than in spring and autumn. In the study domain, winters are generally characterized by the passage of depressions associated with the polar front, which generally exhibits low precipitation intensity, but with a wide horizontal spread (Beguería et al., 2009). In summer, the contributions from convective systems are very important in the total precipitation across the region, accounting for more intense, less frequent rain, with small spatial coverage (Martín-Vide and Olcina, 2001). Unlike winter and summer, precipitation patterns in spring and autumn are different as mixed types of precipitation are likely to occur, especially at the beginning of each season, where local factors (e.g., convective activity) and synoptic patterns can interact with each other and also with sea surface temperature in the Mediterranean region (Ramis et al., 1997). For this reason, it might be expected that an area occupied by either cold or warm cloud during spring and autumn will not be correctly detected by the infrared-based precipitation algorithms in a way similar to those of winter and summer. In their study over the Mediterranean region, Feidas et al. (2008) found that the infrared sensors showed good skill in reproducing precipitation during the summer season (Pearson's $\mathrm{r}=0.9$ ). Feidas et al. attributed this behavior to the convective type of precipitation in summer, which can be well defined by the infrared based precipitation algorithms, especially with the absence of snow and cold air masses in the Mediterranean region during the summertime. The same finding has also been observed using thermal infrared NOAA-AVHRR data over the Iberian Peninsula (Tarruella and Jorge, 2003). The good agreement between rain gauge and TRMM $3 B 42$ during summer can also be seen in the context that this version (V7) of the TRMM precipitation estimates has markedly improved compared to previous versions in terms of the better estimation of the ratio of convective rainfall to total rainfall (Huffman and Bolvin, 2012; Chen et al., 2013).

\subsection{Spatial variations}

The analysis indicated that the TRMM 3B42 tended to overestimate precipitation in the study domain. The only exception was found in the most elevated region (R4), which exhibited an 
overall underestimation across most seasons. The general over-prediction against rain gauge data agrees well with the findings of many previous studies worldwide (e.g., Jobard et al. 2011; Liechti et al. 2012; Yin et al. 2008). For example, Bolvin et al. (2009) reported an overestimation of the mean precipitation in southern Finland, with a relative bias of 89\% during winter. TRMM 3B42 also overestimated rainfall over the Zambezi River Basin (Liechti et al. 2012) and the Tibetan Plateau (Yin et al. 2008). One possible reason for the overestimation of the magnitude of seasonal and annual precipitation in our domain can be seen in the context that TRMM precipitation is retrieved from microwave and infrared sensors, which observe cloud information at upper levels rather than actual precipitation near the surface. Accordingly, a fraction of the estimated precipitation might be expected to evaporate before reaching the ground, or not reach the ground at all, resulting in precipitation overestimation (Rozante and Cavalcanti 2008). In areas of complex topography, knowledge of the distance between the cloud top and the Earth's surface is essential for an accurate infrared retrieval of precipitation amount. This is mainly because this distance can significantly affect the amount of evaporation below the cloud base (Liu and Zipser, 2013). For this reason, it might be necessary to develop a regionally specific version of Z-R relationships over the domain rather than using the global version of TRMM 3B42.

A more detailed inspection of the spatial performance of the TRMM 3B42 suggests that it performs well in locations with lower precipitation (R1 and R2) than in regions with high precipitation (R3 and R4), particularly during the cold season. Given that complex topography exerts strong controls on regional precipitation in the study area, this finding suggests that the capacity of using TRMM 3B42 to explain precipitation regimes decreases significantly with altitude. Over the Southern Appalachian Mountain (USA), Duan et al. (2014) found that the TRMM 3B42 product underestimated rainfall in orographic areas, whereas it largely overestimated it in the valleys and over flat areas. Similarly, Zulkafli et al. (2014) found that the TRMM 3B42 tended to underestimate precipitation in the Andes (northern Peru). In our domain, this finding is interesting from a hydrological perspective, as the rivers originating in the Pyrenees have their maximum flow during spring, contributing to nearly $72 \%$ of the discharge of the Ebro, the largest river in the Iberian Peninsula (Lopez-Moreno et al., 2004; 2008). R1 and R2 are generally situated in areas with lower precipitation, but also over plain altitudes (less than 50 $\mathrm{m})$. The majority of these regions are located within the Ebro depression or in some plateaus associated with moderately elevated areas to the west and southwest (refers to Figure 1). 
572 Accordingly, estimation of precipitation from these open surfaces using microwave sensors is

573 expected to be more accurate than in high and very complex regions. Over complex mountainous

574 regions (R4), the TRMM 3B42 generally failed to adequately reproduce precipitation

575 characteristics. In these areas, snowfall events can occur and snow cover can persist for a few

576 days (Lopez Moreno et al., 2008). The behavior of the TRMM 3B42 in this region could

577 therefore be attributed to the surface snow screening procedure embedded in the TRMM 3B42,

578 particularly during winter and early spring. In particular, snow-covered surfaces cause strong

579 scattering, which limits the ability of microwave algorithms to correctly define scatter signals

580 over land (Huffman and Bolvin, 2008; Hirpa et al., 2010). Ferraro et al. (1998) confirmed the

581 dependency of microwave brightness temperature signals for precipitation estimates on surface

582 type, indicating that different surface types can lead to complex interactions of Earth emitted

583 microwave radiation, which complicates the interpretation of the measured microwave signal.

584 Hirpa et al. (2010) indicated that the passive microwave sensors largely fail to discriminate

585 frozen and surface snow and could even incorrectly classify them as rain clouds. More recently,

586 Stampoulis and Anagnostou (2012) linked errors of microwave sensors and their ability to solve

587 surface snow/ice contamination in the cold season.

588

589 It should be noted that R3 also includes areas of complex terrain like R4, with an average altitude 590 of approximately $718 \mathrm{~m}$, compared to $877 \mathrm{~m}$ for R4. Interestingly, the validation results suggest 591 better performance for R3 and even comparable findings to R1 and R2 in some cases (refer to 592 Figure 3). For example, the average rho coefficients for R3 during winter (0.61), spring (0.60), 593 summer (0.71) and autumn (0.66) were comparable to those of R2, with 0.66 (winter), 0.64 594 (spring), 0.73 (summer) and 0.69 (autumn). These differences can be explained by the fact that 595 the terrain ranges of R4 (e.g., the Pyrenees) are mostly located on the windward side of the 596 westerly and northerly advections, which contribute to more frequent and intense rainfall events 597 (Beguería et al., 2009). In contrast, R3 is located at the foothills of the more complex terrain in 598 R4, with portions of the ranges located in the leeward slopes. Nicholson et al. (2003) found 599 significant differences in the performance of TMPA-7RT between windward and leeward 600 regions over West Africa. Another possible reason is that the distribution of precipitation in the 601 regions of complex terrain (i.e., R3 and R4) is highly variable over space and time and therefore 602 the performance of the TRMM 3B42 at specific locations is very sensitive to the altitude, slope 603 and exposure of these sites (Mätzler and Standley, 2000). Taken together, these spatial 
differences suggest that the impact of the topography on the skill of the TRMM 3B42 is not significant everywhere in the study domain.

Our results also reveal relatively poor agreement between rain gauge and TRMM 3B42 in coastal areas compared to inland regions, suggesting that the TRMM 3B42 does not capture the coastal effect. These spatial variations may be linked to the contamination of the signal in coastal areas. In particular, the coastal areas in our domain are located between either the Mediterranean or the Cantabric Sea and the mountain ranges (e.g., Catalan chain along the Mediterranean and the Cantabric system along the Cantabric Sea). The joint impact of the sea and mountains can likely induce a failure of the sensor to discriminate between land and water pixels. This behavior is more likely to be expected in the areas where the coastal mountains closely approach the sea, leading to narrow coastlines (e.g., the Cantabric coastline). In the same context, the TRMM 3B42 grid boxes over land, which are available at a spatial resolution of $25 \mathrm{~km}$, may partially incorporate portions of the neighboring water body. These maritime portions are not represented by rain gauges and the grid average precipitation can accordingly be different from that of the gauge data. In their assessment of the performance of the TRMM-3B43 precipitation product over Kyrgyzstan, Karaseva et al. (2012) noted that the TRMM-3B43 showed the lowest correlation with rain gauge data in maritime areas (Pearson's $r=0.17-0.19$ ), compared with inland regions (Pearson’s r=0.36-0.88).

\subsection{Performance of precipitation extremes}

TRMM 3B42 was evaluated in terms of categorical performance by using different daily precipitation thresholds. The FBI values for very light rain events $\left(<1 \mathrm{~mm}\right.$.day $\left.{ }^{-1}\right)$ were far from the perfect value, indicating that there was a higher degree of disagreement between rain gauges and TRMM 3B42 in terms of their capability of reproducing the occurrence of precipitation during light rain events. In contrast, the FBI suggested an underestimation of precipitation occurrence during moderate (5-25 mm.day ${ }^{-1}$ ) rain events. Higher precipitation ranges (>25 mm.day ${ }^{-1}$ ) showed a contradictory trend as the FBI values suggested an underestimation of these events during the cold season (winter and spring), whereas they were overestimated in the warm season (summer and autumn). In accordance with FBI results, other skill metrics (e.g., FAR, POD and TS) also agree that the TRMM 3 B42 showed a near perfect skill for predicting moderate rain events, while it had difficulties in accurately estimating both light and heavy rainfall events. The poor performance of the TRMM 3B42 in correctly detecting light and high 
637

638

639

640

641

642

643

644

645

646

647

648

649

650

651

652

653

654

655

656

657

658

659

660

661

662

663

664

665

666

667

668

669

rainfall events was also reported by Prakash et al. (2012) in the north Indian Ocean and by Chokngamwong and Chiu (2008) in Thailand. For example, Prakash and Gairola (2014) found that the major differences between TRMM estimates and buoy gauge over the tropical Indian Ocean were found during days of very light precipitation rate $\left(<0.5 \mathrm{~mm}^{-d a y}{ }^{-1}\right)$ and higher precipitation rates (> $100 \mathrm{~mm} \cdot$ day $^{-1}$ ). Huffman et al. (2007) also reported that the TRMM multisatellite precipitation estimates show low skill in correctly specifying light daily rainfall events. Similarly, Habib et al. (2009) showed a considerable overestimation of lower precipitation rates and underestimation of higher precipitation rates by TRMM in the southern US.

In the study domain, anticyclonic conditions are among the most frequent weather types during winter, representing almost 37\% of the winter total days (Vicente-Serrano and Lopez-Moreno, 2006). Therefore, it might be expected that the occurrence of intense rain events will be underestimated during these anticyclonic days as a consequence of the dominance of stable cold air masses. Considering that most of the heavy rainfall events will be characterized at small spatial scales, the underestimation of heavy events by TRMM 3B42 can be explained by the inadequate sampling of the microwave sensors over time, which can result in missing these very local and short-duration rain events. The TRMM 3B42 spatial resolution (25 km) is probably inadequate to reproduce local summer extreme precipitation events. The nature of precipitation data might also be another possible explanation of the negative bias of extreme events as the spatial average of heavy events derived from the TRMM 3B42 can be different from that of the observed data. This is simply because rain gauge data were provided at a point scale, whereas TRMM 3B42 data were compiled as grids with a spatial interval of $25 \mathrm{~km}$. These differences might be explained by inherent scale effects, which constrain direct comparison between the point-based station estimates and the TRMM grid outputs. Over the study domain, real-world boundary conditions (e.g., topography, leeside effects and land use/cover changes) may vary over short distances, particularly in mountainous areas. Incorporating such small scale changes and features into TRMM estimates $\left(0.25^{\circ}\right.$ by $0.25^{\circ}$ pixels) remains a challenge. In contrast to wintertime, the overestimation of the occurrence of high rain events during summer can be seen in the context that summer precipitation is mostly associated with convective activity that exhibits a strong updraft and accordingly a large canopy of colder cloud top temperatures (Goodman et al., 1988). Given that infrared techniques assume that colder cloud-top temperatures are always associated with higher rain rates, heavy precipitation events during summer are more likely to be over-predicted by these techniques. 


\section{Conclusions}

671 An evaluation of the capabilities of the TRMM 3B42 estimates to reproduce the spatial and 672 temporal characteristics of observed precipitation in north-eastern Iberia, a region characterized 673 by heterogeneous terrain, was undertaken. A total of 12 years of data (1998-2009) from a high674 density network of rain gauges was employed for the evaluation purpose. The assessment was 675 conducted on a daily basis and considered four sub-regions, which display different and distinct 676 precipitation regimes. The \%BIAS, MAE, RMSE and Spearman rho correlation coefficient were 677 derived for the TRMM 3B42 with respect to in-situ rain gauge data. The results indicated that the 678 performance of the TRMM 3B42 is seasonally dependent, with the best results identified in 679 winter and summer rather than in spring and autumn. The comparison of daily data between 680 observations and TRMM 3B42 data yielded reasonable results, with an overall bias of $18.7 \%$. 681 The MAE was found to be less than 2.5 mm.day ${ }^{-1}$, whereas the RMSE was 6.4 mm.day $^{-1}$. 682 Spatially, the TRMM 3B42 showed better skill in regions with less precipitation and low altitude 683 (e.g., the Ebro valley), whereas the skill deteriorated along the coastal areas (e.g., the Cantabric 684 region) and in regions of complex terrain (e.g., the Pyrenees).

685

686

687

688

A set of skill metrics were also used to evaluate the ability of the TRMM 3B42 to reproduce the occurrence of precipitation at different daily precipitation thresholds. All statistics for daily precipitation agree that the TRMM 3B42 shows reasonable skill for moderate precipitation (5-25 689 mm.day $\left.{ }^{-1}\right)$, but they sharply decrease at very low $\left(<1 \mathrm{~mm}^{-d a y^{-1}}\right)$ and upper (more than 50 690 mm.day ${ }^{-1}$ ) thresholds. Similarly, TRMM 3B42 underestimated rainfall rates during high precipitation events, whereas it overestimated rainfall during light precipitation events. The 692 693 performance of the TRMM 3B42 was reversed for the occurrence frequency, with an overestimation of high rain events and an underestimation of light rain events.

694

695

696

The use of a dense network of precipitation measurements contributes significantly to a detailed regional assessment of the performance of the TRMM 3B42 product in the study domain. In 697 general, the results demonstrate that the TRMM precipitation product shows good agreement 698 with gauge data in inland regions and in areas of low altitude. Nonetheless, the results also confirm the limitations of the TRMM 3B42 precipitation estimates in regions of complex 700 topography. In this regard, other space-based products (e.g., PERSIANN and CMORPH) could 701 be a venue for future research to assess their performance, particularly in response to topography 
708

709

710

711

712

713

714

715

716

717

718

719

720

721

722

723

724

725

726

727

728

729

730

731

732

733

734

735

736

737

738

739

740

741

and distance to surrounding water bodies across the study domain. Overall, this work highlights the need for improving the algorithms of the TRMM precipitation estimation over areas of heterogeneous terrain in order to better represent medium and high precipitation events. Such improvements are likely to enhance hydrological and meteorological applications in the region, including hydrological modeling, drought assessment, flood forecasting and an examination of the observed impacts of changes in hydroclimatology.

\section{Acknowledgements}

Research reported in this publication was supported by the King Abdullah University of Science and Technology (KAUST), Saudi Arabia. This work has also been supported by the research project LIFE12 ENV/ES/000536 (Demonstration and validation of innovative methodology for regional climate change adaptation in the Mediterranean area-LIFE MEDACC) financed by the LIFE program of the European Commission. We acknowledge the National Aeronautics and Space Administration (NASA) for providing the TRMM dataset and the Spanish State Meteorological Agency (AEMET) for providing precipitation observations.

\section{References}

Adeyewa, Z. D., and K. Nakamura (2003), Validation of TRMM radar rainfall data over major climatic regions in Africa, Journal of Applied Meteorology, 42(2), 331-347, doi: 10.1175/1520-0450.

Behrangi, A., B. Khakbaz, T. C. Jaw, A. AghaKouchak, K. L. Hsu, and S. Sorooshian (2011), Hydrologic evaluation of satellite precipitation products over a mid-size basin, Journal of Hydrology, 397(3-4), 225-237, doi: 10.1016/j.jhydrol.2010.11.043.

Beguería, S., Sergio M. Vicente-Serrano, Juan I. López-Moreno and García-Ruiz, J.M. (2009). Annual and seasonal mapping of peak intensity, magnitude and duration of extreme precipitation events across a climatic gradient, northeast Spain. Int. J. Climatol. 29: 1759-1779.

Chen, S., Hong, Y., Gourley, J., Huffman, G., Tian, Y., Cao, Q., Yong, B., Kirstetter, P., Hu, J., Hardy, J., Li, Z., Khan, S., and X Xue (2013). Evaluation of the successive V6 and V7 TRMM multisatellite precipitation analysis over the Continental United States, Water Resources Research, 49(12), 8174-8186, doi: 10.1002/2012wr012795.

Chokngamwong, R., and L. S. Chiu (2008), Thailand daily rainfall and comparison with TRMM products, Journal of Hydrometeorology, 9(2), 256-266, doi: 10.1175/2007jhm876.1.

Duan, Y., A. M. Wilson, and A. P. Barros (2014), Scoping a field experiment: error diagnostics of TRMM precipitation radar estimates in complex terrain as a basis for IPHEx2014, Hydrology and Earth System Sciences Discussions, 11(10), 11137-11182, doi:10.5194/hessd-11-11137-2014.

Ebert, E. E., J. E. Janowiak, and C. Kidd (2007), Comparison of near-real-time precipitation estimates from satellite observations and numerical models, Bulletin of the American Meteorological Society, 88(1), 47-64, doi:10.1175/Bams-88-1-47. 
El Kenawy, A, López-Moreno, J. I., Brunsell, N. A., and S. M. Vicente-Serrano (2013), Anomalously severe cold nights and warm days in northeastern Spain: their spatial variability, driving forces and future projections, Global and Planetary Change, 101, 1232. doi:10.1016/j.gloplacha.2012.11.011.

Evans, J. P., and M. F. McCabe (2013) Effect of model resolution on a regional climate model simulation over southeast Australia. Clim Res 56:131-145, doi:10.3354/cr01151.

Feidas, H., G. Kokolatos, A. Negri, M. Manyin, N. Chrysoulakis, and Y. Kamarianakis (2009), Validation of an infrared-based satellite algorithm to estimate accumulated rainfall over the Mediterranean basin, Theor Appl Climatol, 95(1-2), 91-109, doi:10.1007/s00704007-0360-y.

Ferraro, R. R., E. A. Smith, W. Berg, and G. J. Huffman (1998), A screening methodology for passive microwave precipitation retrieval algorithms, Journal of the Atmospheric Sciences, 55(9), 1583-1600, doi:10.1175/1520-0469(1998)055<1583:Asmfpm>2.0.Co;2.

Font-Tullot, I. (1983), Climatología de España y Portugal, Sección de Publicaciones del Instituto Nacional de Meteorología, Madrid.

Goodman, S. J., D. E. Buechler, and P. J. Meyer (1988), Convective Tendency Images Derived from a Combination of Lightning and Satellite Data, Weather and Forecasting, 3(3), 173188, doi:10.1175/1520-0434.

Groisman, P. Y., and D. R. Legates (1994), The Accuracy of United-States Precipitation Data, Bulletin of the American Meteorological Society, 75(2), 215-227, doi:10.1175/15200477.

Habib, E., Henschke A., and R. Adler (2009). Evaluation of TMPA satellite-based research and real-time rainfall estimates during six tropical-related heavy rainfall events over Louisiana, USA, Atmos. Res. 94, 373-388.

Heidinger, H., C. Yarleque, A. Posadas, and R. Quiroz (2012), TRMM rainfall correction over the Andean Plateau using wavelet multi-resolution analysis, International Journal of Remote Sensing, 33(14), 4583-4602, doi:10.1080/01431161.2011.652315.

Hirpa, F. A., M. Gebremichael, and T. Hopson (2010), Evaluation of High-Resolution Satellite Precipitation Products over Very Complex Terrain in Ethiopia, Journal of Applied Meteorology and Climatology, 49(5), 1044-1051, doi:10.1175/2009jamc2298.1.

Huffman, G. J., R. F. Adler, P. Arkin, A. Chang, R. Ferraro, A. Gruber, J. Janowiak, A. McNab, B. Rudolf, and U. Schneider (1997), The Global Precipitation Climatology Project (GPCP) Combined Precipitation Dataset, Bulletin of the American Meteorological Society, 78(1), 5-20, doi:10.1175/1520-0477.

Huffman, G. J., R. F. Adler, D. T. Bolvin, G. J. Gu, E. J. Nelkin, K. P. Bowman, Y. Hong, E. F. Stocker, and D. B. Wolff (2007), The TRMM multisatellite precipitation analysis (TMPA): Quasi-global, multiyear, combined-sensor precipitation estimates at fine scales, Journal of Hydrometeorology, 8(1), 38-55, doi:10.1175/Jhm560.1.

Huffman, G. J., and Bolvin, D. T. (2008), TRMM and other data precipitation data set documentation (TRMM 3B42 3B43 doc), laboratory for atmospheres, NASA Goddard C825 space flight center and science systems and applications.

Huffman, G. J., Bolvin, D.T., (2012), TRMM and other data precipitation data set documentation, (ftp://precip.gsfc.nasa.gov/pub/trmmdocs/3B42_3B43_doc.pdf). Last access (accessed on 13 December 2014).

Islam, T., M. A. Rico-Ramirez, D. W. Han, P. K. Srivastava, and A. M. Ishak (2012), Performance evaluation of the TRMM precipitation estimation using ground-based radars from the GPM validation network, Journal of Atmospheric and Solar-Terrestrial Physics, 77, 194-208, doi:10.1016/j.jastp.2012.01.001. 
Jobard, I., F. Chopin, J. C. Berges, and R. Roca (2011), An intercomparison of 10-day satellite precipitation products during West African monsoon, International Journal of Remote Sensing, 32(9), 2353-2376, doi:10.1080/01431161003698286.

Karaseva, M. O., S. Prakash, and R. M. Gairola (2012), Validation of high-resolution TRMM3B43 precipitation product using rain gauge measurements over Kyrgyzstan, Theor Appl Climatol, 108(1-2), 147-157, doi:10.1007/s00704-011-0509-6.

Kidd, C., P. Bauer, J. Turk, G. J. Huffman, R. Joyce, K. L. Hsu, and D. Braithwaite (2012), Intercomparison of High-Resolution Precipitation Products over Northwest Europe, Journal of Hydrometeorology, 13(1), 67-83, doi:10.1175/jhm-d-11-042.1.

Kummerow, C., W. Barnes, T. Kozu, J. Shiue, and J. Simpson (1998), The Tropical Rainfall Measuring Mission (TRMM) sensor package, Journal of Atmospheric and Oceanic Technology, 15(3), 809-817, doi:10.1175/1520-0426.

Liechti, C. T., J. P. Matos, J. L. Boillat, and A. J. Schleiss (2012), Comparison and evaluation of satellite derived precipitation products for hydrological modeling of the Zambezi River Basin, Hydrol Earth Syst Sc, 16(2), 489-500, doi:10.5194/hess-16-489-2012.

Levizzani, V., Bauer, P., Turk, F. Joseph (2007), Measuring Precipitation from Space: EURAINSAT and the Future, 722 pp., Springer.

Liu, C., and E. J. Zipser (2013), Why does radar reflectivity tend to increase downward toward the ocean surface, but decrease downward toward the land surface?, Journal of Geophysical Research: Atmospheres, 118(1), 135-148, doi:10.1029/2012jd018134.

Lockhoff, M., O. Zolina, C. Simmer, and J. Schulz (2014), Evaluation of Satellite-Retrieved Extreme Precipitation over Europe using Gauge Observations, Journal of Climate, 27(2), 607-623, doi:10.1175/jcli-d-13-00194.1.

López-Moreno, J.I. and J.M. García-Ruiz (2004), Influence of snow accumulation and snowmelt on streamflow in the Central Spanish Pyrenees. International Journal of Hydrological Sciences49 (5): 787-802.

López-Moreno, J. I., S. Goyette, and M. Beniston (2008), Climate change prediction over complex areas: spatial variability of uncertainties and predictions over the Pyrenees from a set of regional climate models, International Journal of Climatology, 28(11), 15351550, doi:10.1002/joc.1645.

López-Moreno, J.I., Vicente-Serrano, S.M., Beguería, S., El Kenawy, A.M., M. Angulo (2010). Trends in daily precipitation on the north-eastern Iberian Peninsula, 19552006.InternationalJournal of Climatology 120: 248-257.

Lorenz, C., and H. Kunstmann (2012), The Hydrological Cycle in Three State-of-the-Art Reanalyses: Intercomparison and Performance Analysis, Journal of Hydrometeorology, 13(5), 1397-1420, doi:10.1175/Jhm-D-11-088.1.

Masunaga, H., T. Iguchi, R. Oki, and M. Kachi (2002), Comparison of rainfall products derived from TRMM microwave imager and precipitation radar, Journal of Applied Meteorology, 41(8), 849-862, doi:10.1175/1520-0450.

Mätzler, C., and A. Standley (2000), Technical note: Relief effects for passive microwave remote sensing, International Journal of Remote Sensing, 21(12), 2403-2412, doi:10.1080/01431160050030538.

Nicholson, S. E., B. Some, J. McCollum, E. Nelkin, D. Klotter, Y. Berte, B. M. Diallo, I. Gaye, G. Kpabeba, O. Ndiaye, J. N. Noukpozounkou, M. M. Tanu, A. Thiam, A. A. Toure, and A. K. Traore (2003), Validation of TRMM and other rainfall estimates with a highdensity gauge dataset for West Africa. Part I: Validation of GPCC rainfall product and pre-TRMM satellite and blended products, Journal of Applied Meteorology, 42(10), 1337-1354, doi:10.1175/1520-0450. 
Prakash, S., and R. M. Gairola (2014), Validation of TRMM-3B42 precipitation product over the tropical Indian Ocean using rain gauge data from the RAMA buoy array, Theor Appl Climatol, 115(3-4), 451-460, doi:10.1007/s00704-013-0903-3.

Prakash, S., A. K. Mitra, I. M. Momin, D. S. Pai, E. N. Rajagopal, and S. Basu (2014), Comparison of TMPA-3B42 versions 6 and 7 Precipitation Products with Gauge based Data over India for the South-West Monsoon Period, Journal of Hydrometeorology, 141006071153004, doi:10.1175/jhm-d-14-0024.1.

Ramis C, Llasat MC, Genovés A, A. Jansá (1997). The october, 1987 floods in Catalonia: synoptic and meso-scale mechanisms. Meteorological Applications 1: 337-350.

Rozante, J. R., and I. F. D. A. Cavalcanti (2008), Regional Eta model experiments: SALLJEX and MCS development, J Geophys Res-Atmos, 113(D17), D17106, Doi 10.1029/2007jd009566.

Sapiano, M. R. P., and P. A. Arkin (2009), An Intercomparison and Validation of HighResolution Satellite Precipitation Estimates with 3-Hourly Gauge Data, Journal of Hydrometeorology, 10(1), 149-166, doi:10.1175/2008jhm1052.1.

Scarsoglio, S., F. Laio, and L. Ridolfi (2013), Climate Dynamics: A Network-Based Approach for the Analysis of Global Precipitation. PLoS ONE 8(8): e71129. doi: 10.1371/journal.pone.0071129.

Seo, D.J, J. P. Briedenbach, and E. R. Johnson (1999), Real-time estimation of mean field bias in radar rainfall data. J. Hydrol., 223, 131- 147.

Shrestha, D., P. Singh, and K. Nakamura (2012), Spatiotemporal variation of rainfall over the central Himalayan region revealed by TRMM Precipitation Radar, J Geophys ResAtmos, 117(D22), D22106, doi 10.1029/2012jd018140.

Stampoulis, D., and E. N. Anagnostou (2012), Evaluation of Global Satellite Rainfall Products over Continental Europe, Journal of Hydrometeorology, 13(2), 588-603, doi:10.1175/Jhm-D-11-086.1.

Su, F. G., Y. Hong, and D. P. Lettenmaier (2008), Evaluation of TRMM Multisatellite Precipitation Analysis (TMPA) and its utility in hydrologic prediction in the La Plata Basin, Journal of Hydrometeorology, 9(4), 622-640, doi:10.1175/2007jhm944.1.

Tarruella, R., J. Jorge (2003). Comparison of three infrared satellite techniques to estimate accumulated rainfall over the Iberian Peninsula. International Journal of Climatology, 23 (14), pp. 1757-1769.

Vicente-Serrano, S. M., and J. I. Lopez-Moreno (2006), The influence of atmospheric circulation at different spatial scales on winter drought variability through a semi-arid climatic gradient in North-east Spain, International Journal of Climatology, 26(11), 1427-1453, doi:10.1002/Joc.1387.

Vicente-Serrano, S. M., S. Begueria, J. I. Lopez-Moreno, M. A. Garcia-Vera, and P. Stepanek (2010), A complete daily precipitation database for north-east Spain: reconstruction, quality control, and homogeneity, International Journal of Climatology, 30(8), 11461163, doi:10.1002/Joc.1850.

Vila, D. A., L. G. G. de Goncalves, D. L. Toll, and J. R. Rozante (2009), Statistical Evaluation of Combined Daily Gauge Observations and Rainfall Satellite Estimates over Continental South America, Journal of Hydrometeorology, 10(2), 533-543, doi:10.1175/2008jhm1048.1.

Wilks, D. S. (1995), Statistical methods in the atmospheric sciences. Academic Press, 704pp.

Yin, Z. Y., X. Q. Zhang, X. D. Liu, M. Colella, and X. L. Chen (2008), An assessment of the biases of satellite rainfall estimates over the Tibetan Plateau and correction methods based on topographic analysis, Journal of Hydrometeorology, 9(3), 301-326, doi:10.1175/2007jhm903.1. 
895

896

897

898

899

900

901

902

903

904

905

906

907

908

909

910

911

912

913

914

915

916

917

918

919

920

921

922

923

924

925

926

927

928

929

930

931

932

933

934

935

Yu, Z., H. Yu, P. Chen, C. Qian, and C. Yue (2009), Verification of Tropical Cyclone-Related Satellite Precipitation Estimates in Mainland China, Journal of Applied Meteorology and Climatology, 48(11), 2227-2241, doi:10.1175/2009jamc2143.1.

Zulkafli, Z., W. Buytaert, C. Onof, B. Manz, E. Tarnavsky, W. Lavado, and J.-L. Guyot (2014), A Comparative Performance Analysis of TRMM 3B42 (TMPA) Versions 6 and 7 for Hydrological Applications over Andean-Amazon River Basins, Journal of Hydrometeorology, 15(2), 581-592, doi:10.1175/jhm-d-13-094.1. 
936 Table I: The structure of the $2 \times 2$ contingency table summarizing the agreement between 937 rain gauge and TRMM data sets for each precipitation threshold.

938

\begin{tabular}{lll}
\hline & \multicolumn{2}{c}{ Rain gauge } \\
\hline & a & b \\
\hline & Yes "hits" & Yes "misses" \\
\hline
\end{tabular}

939

940

941

942

943

944

945

946

947

948

949

950

951

952

953

954

955

956

957

958

959

960

961

962

963

964

965 
966 Table II. Spearman rho correlation coefficients calculated between rain gauge and TRMM 967 3B42 data.

\begin{tabular}{lllll}
\hline & DJF & MAM & JJA & SON \\
\hline R1 & 0.71 & 0.66 & 0.73 & 0.72 \\
R2 & 0.66 & 0.64 & 0.73 & 0.69 \\
R3 & 0.61 & 0.60 & 0.71 & 0.66 \\
R4 & 0.47 & 0.46 & 0.60 & 0.54 \\
All domain & 0.61 & 0.59 & 0.69 & 0.65 \\
\hline
\end{tabular}

968

969

970

971

972

973

974

975

976

977

978

979

980

981

982

983

984

985

986

987 


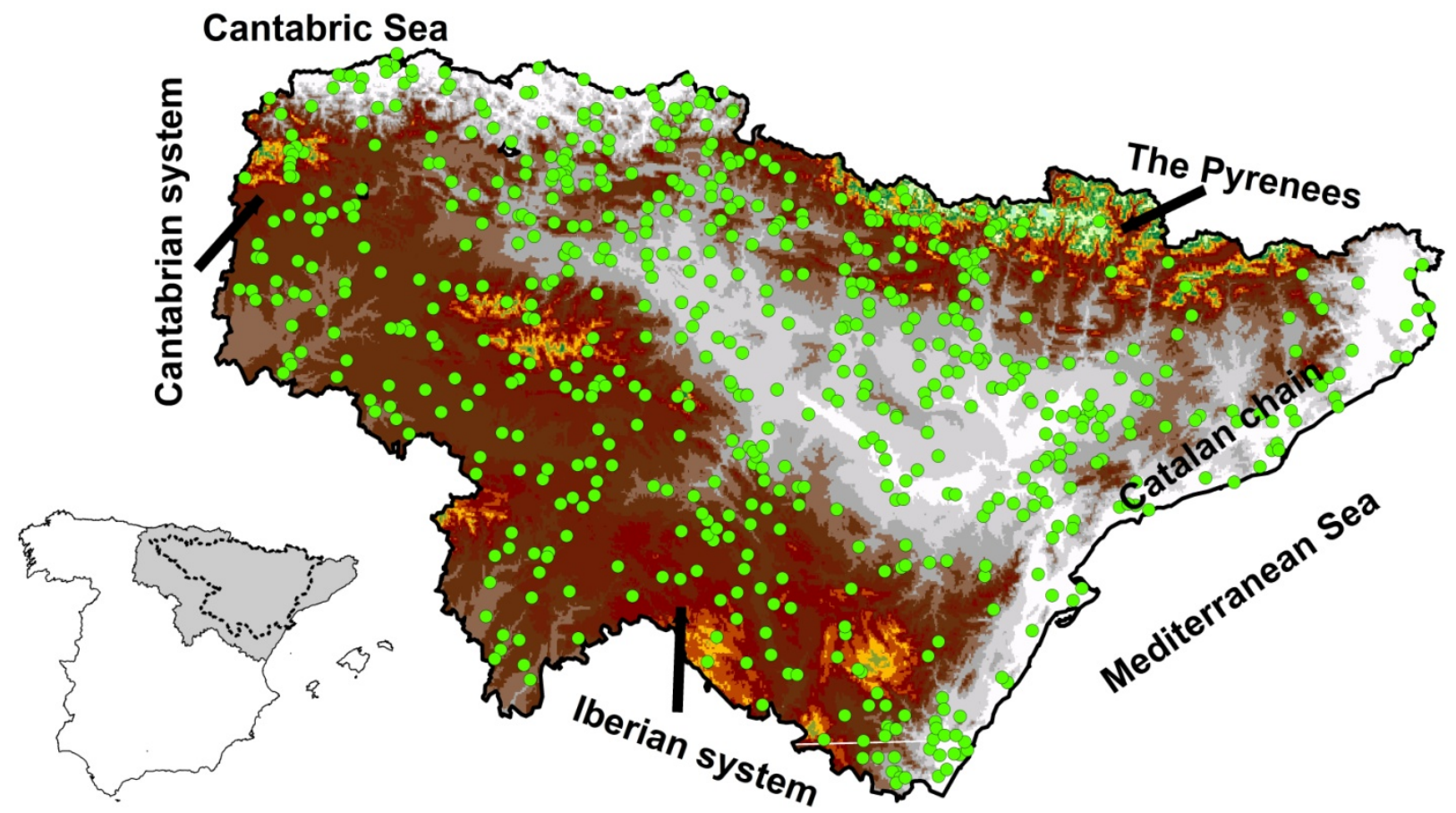

988

989

990

991

992

993

994

995

996

997

998

999

1000

1001

1002

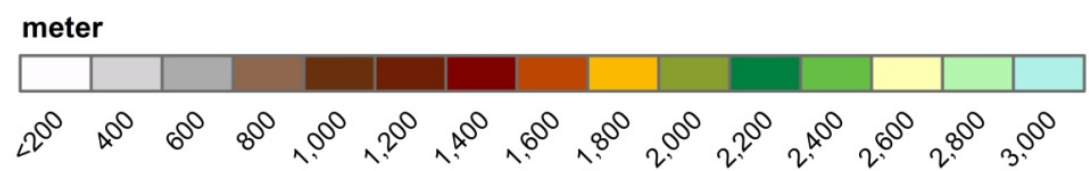

Figure 1: The spatial distribution of the 656 rain gauges and topography of the study domain. The Ebro basin is outlined by the bold line. 
(a)

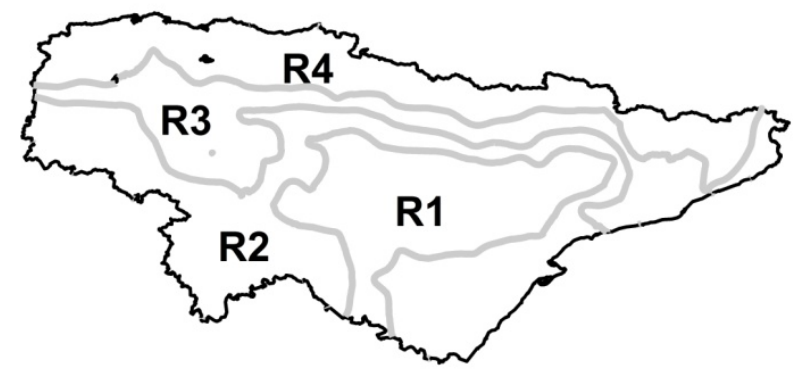

1003

1004

1005

1006

1007

1008

1009

1010

1011

1012

1013

1014

1015

1016

1017

1018

1019

1020

1021

1022

1023 altitude. (b)

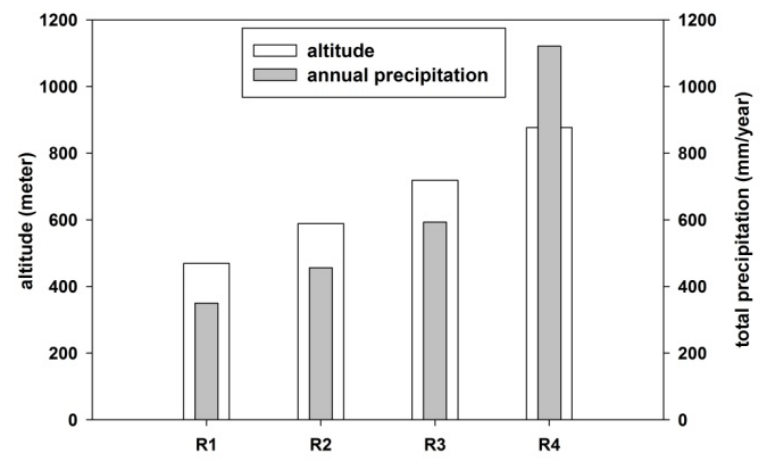

Figure 2: (a) Spatial distribution and boundaries of the four main sub-regions and (b) the differences between the sub-regions as a function of the annual total rainfall and average 

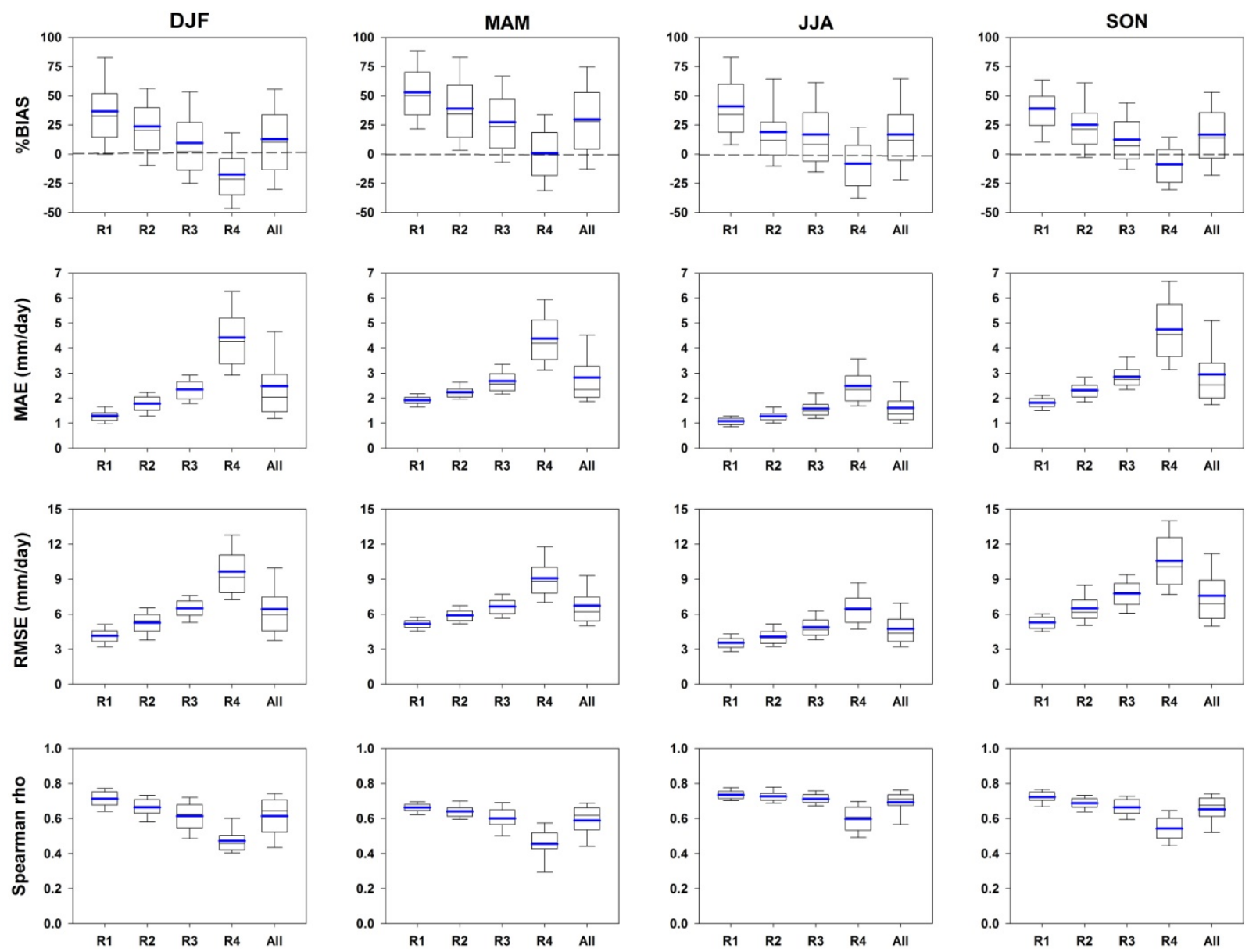

1025 1026

1027

1028

1029

1030

1031

1032

1033

1034

1035

1036

1037

1038

1039

1040

1041

1042

1043

1044

1045

1046

Figure 3: Results of the different validation estimators for each sub-region and for the whole domain. In the box plots, the central black line indicates the median, whereas the central blue line refers to the mean. The horizontal lines of each plotted box plot illustrate the $10^{\text {th }}, 25^{\text {th }}, 75^{\text {th }}$ and $90^{\text {th }}$ percentiles, respectively. The dashed line in the upper panels indicates no differences between observed and TRMM data. 
1051

1052

1053

1054

1055

1056

1057

1058

1059

1060

1061

1062

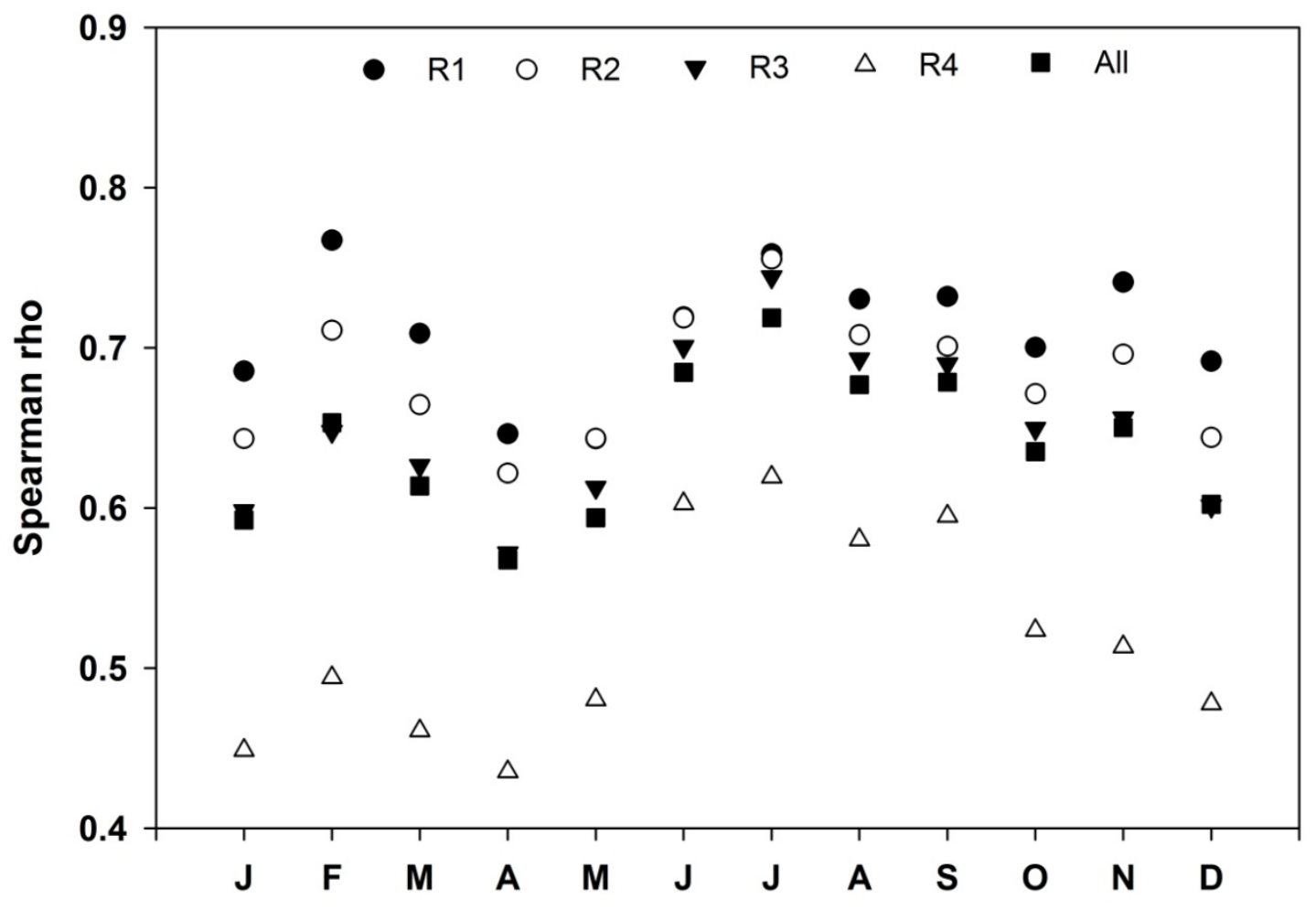

Figure 4: Monthly variations of Spearman rho coefficient averaged for each sub-region and for the whole domain. 

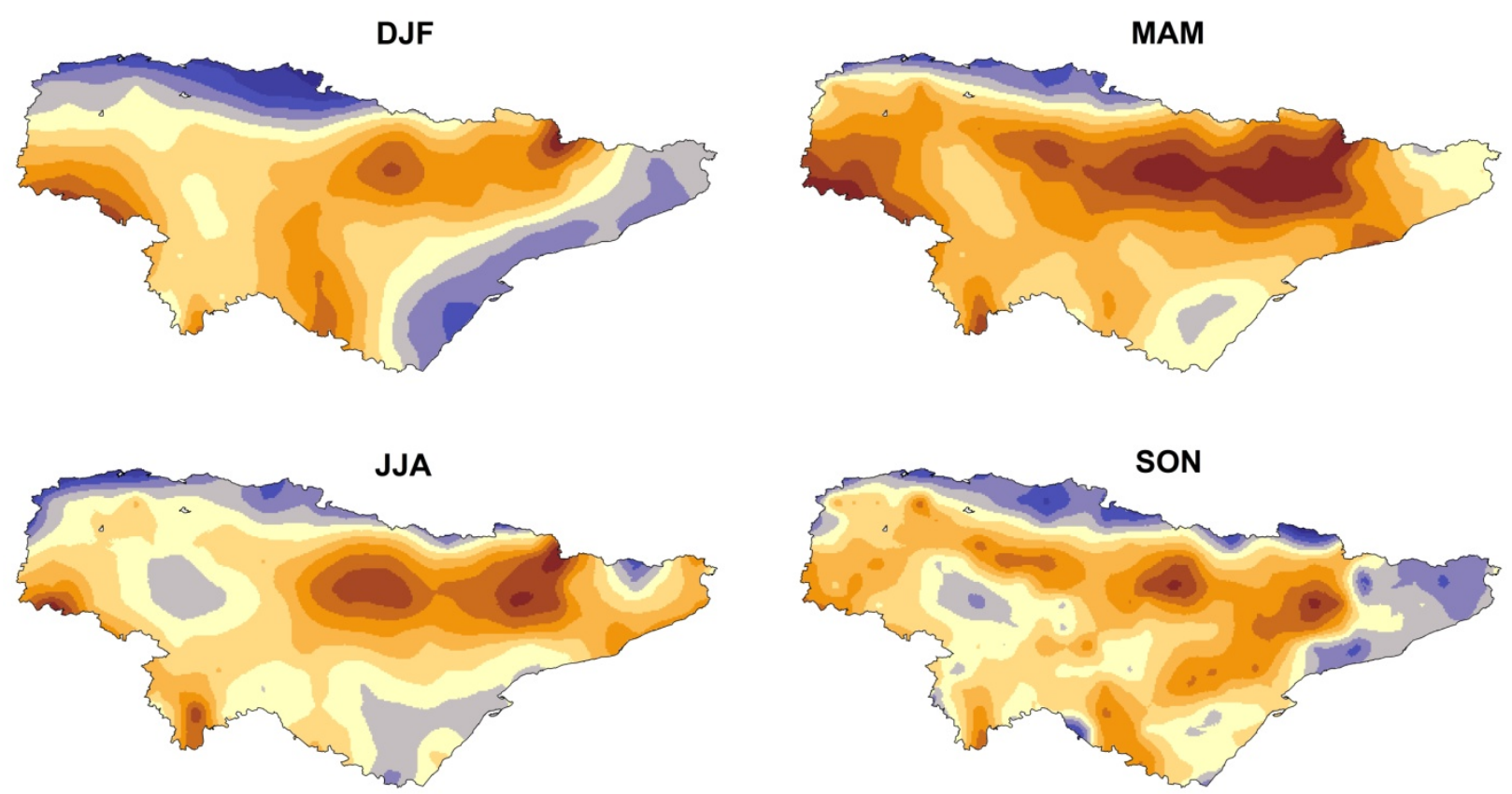

1063

1064 1065

1066

1067

1068

1069

1070

1071

1072

1073

1074

1075

1076

1077

1078

$\%$

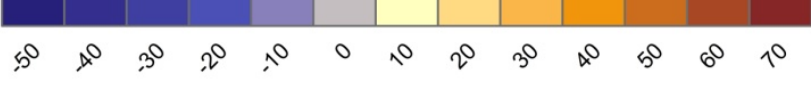

Figure 5: Spatial distribution of the \%BIAS averaged for the period 1998-2009.

8



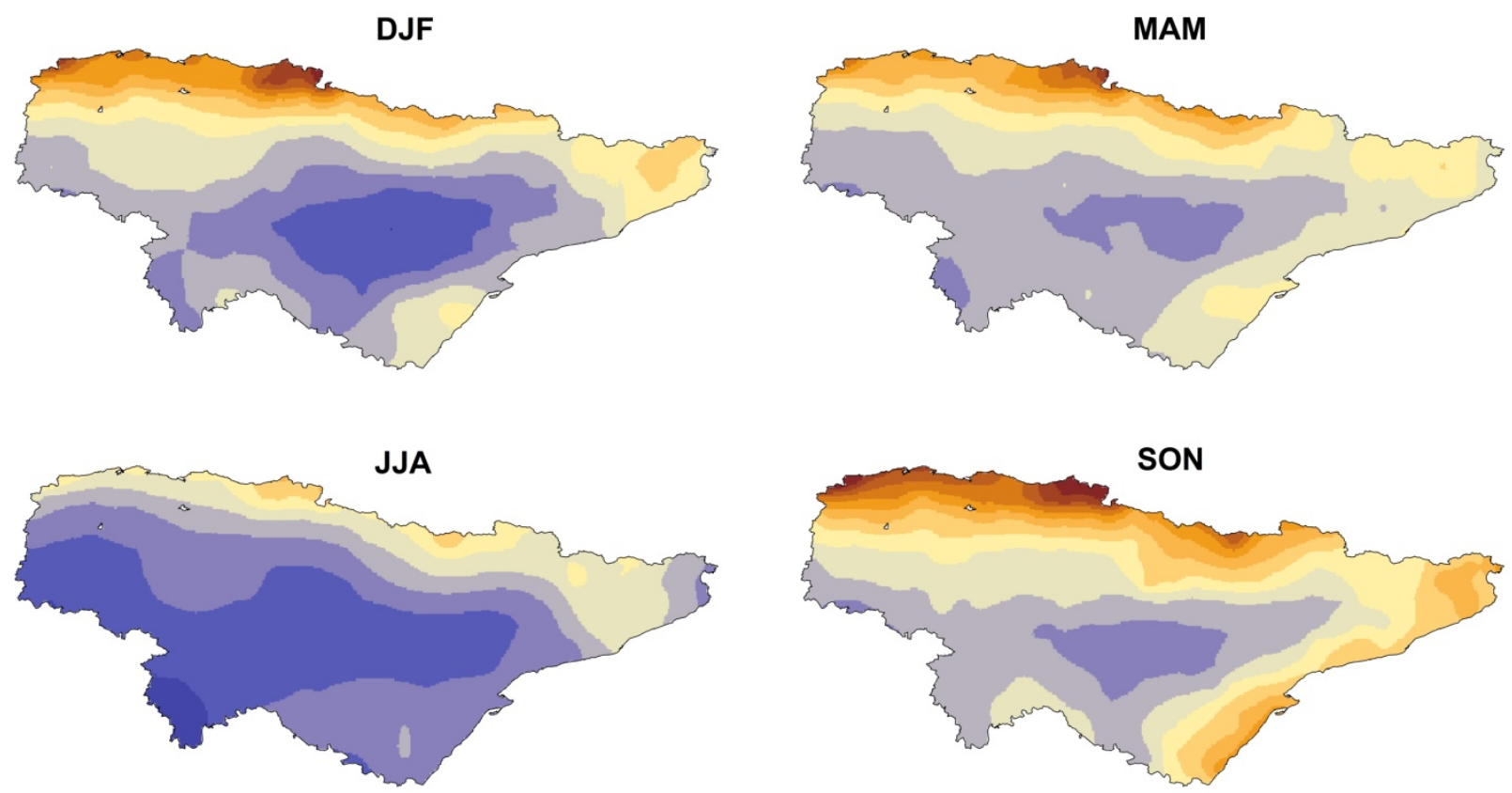

$\mathrm{mm} /$ day

1079

1080 1081

1082

1083

1084

1085

1086

1087

1088

1089

1090

1091

1092

1093

1094

1095

1096 

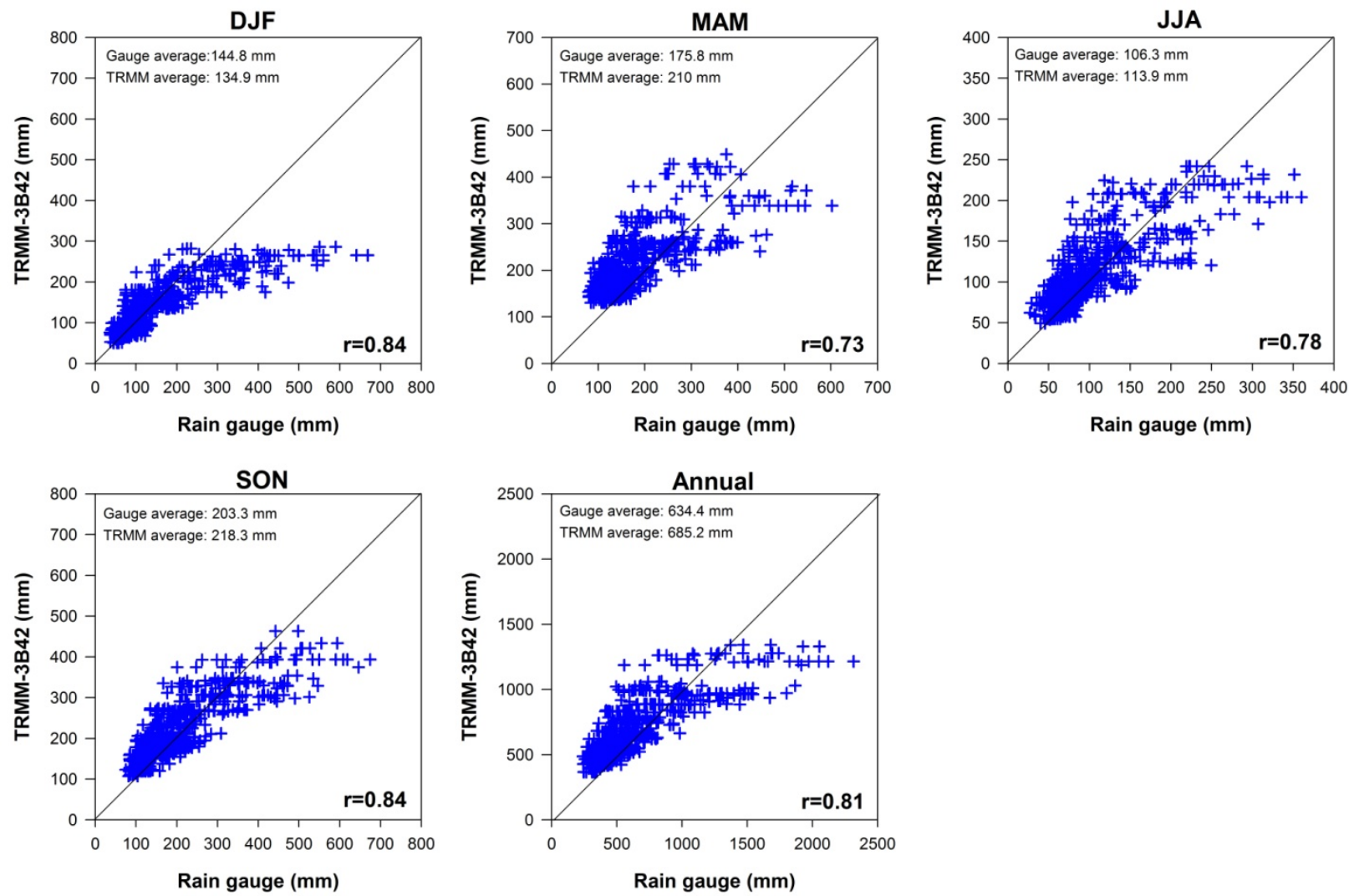

Figure 7: Scatter plots showing mean seasonal and annual accumulated precipitation (mm) of rain gauges versus TRMM $3 B 42$ data. Pearson correlation coefficient is also provided for each season. 

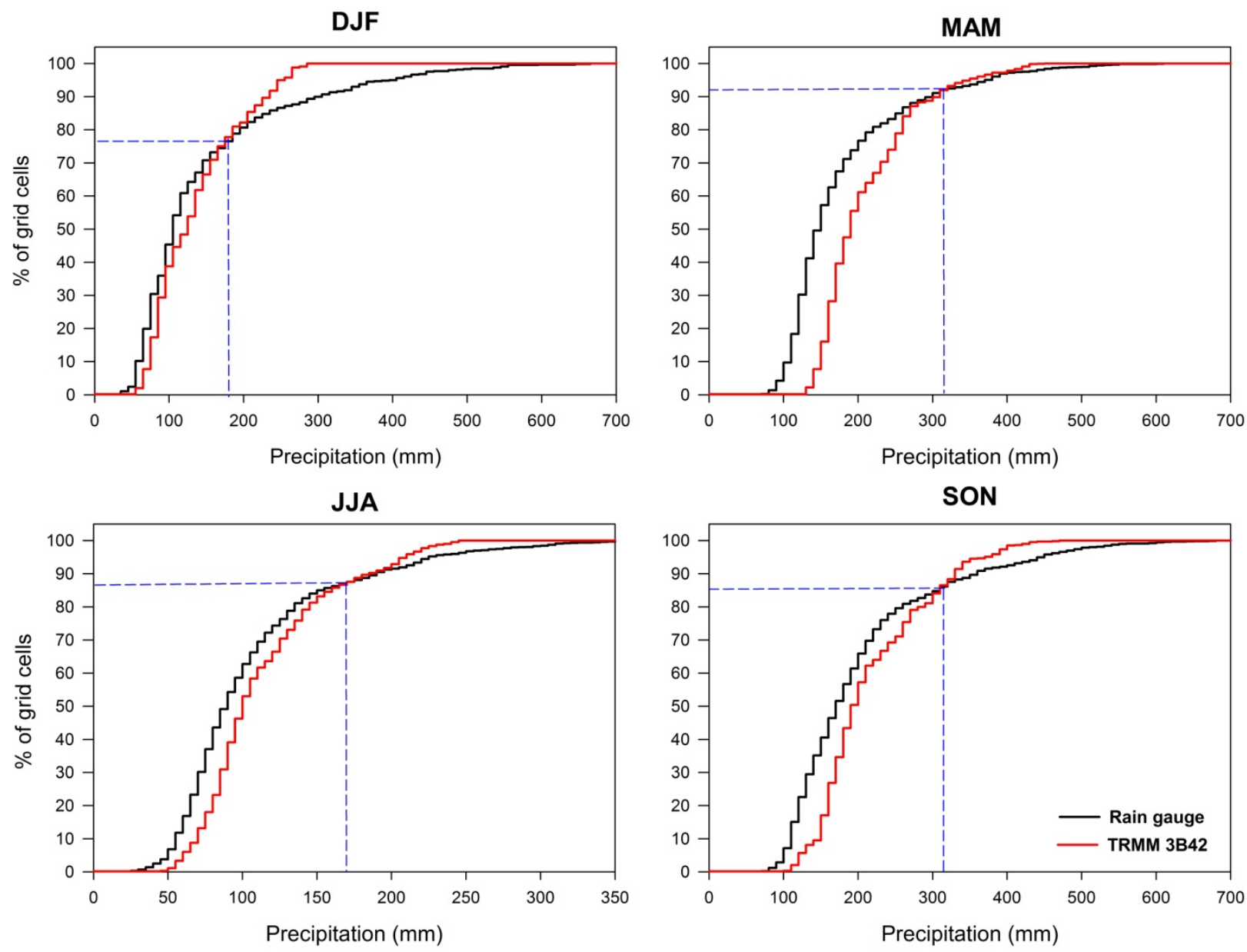

1116

1117

1118

1119

1120

1121

1122

1123

1124

1125

1126

1127

1128

1129

1130

1131

1132

Figure 8: Cumulative frequency plot for seasonal accumulated precipitation using rain gauge and TRMM 3B42 data. The vertical blue line indicates the threshold at which the count of rain gauges showed a reverse behavior compared to TRMM $3 B 42$. 

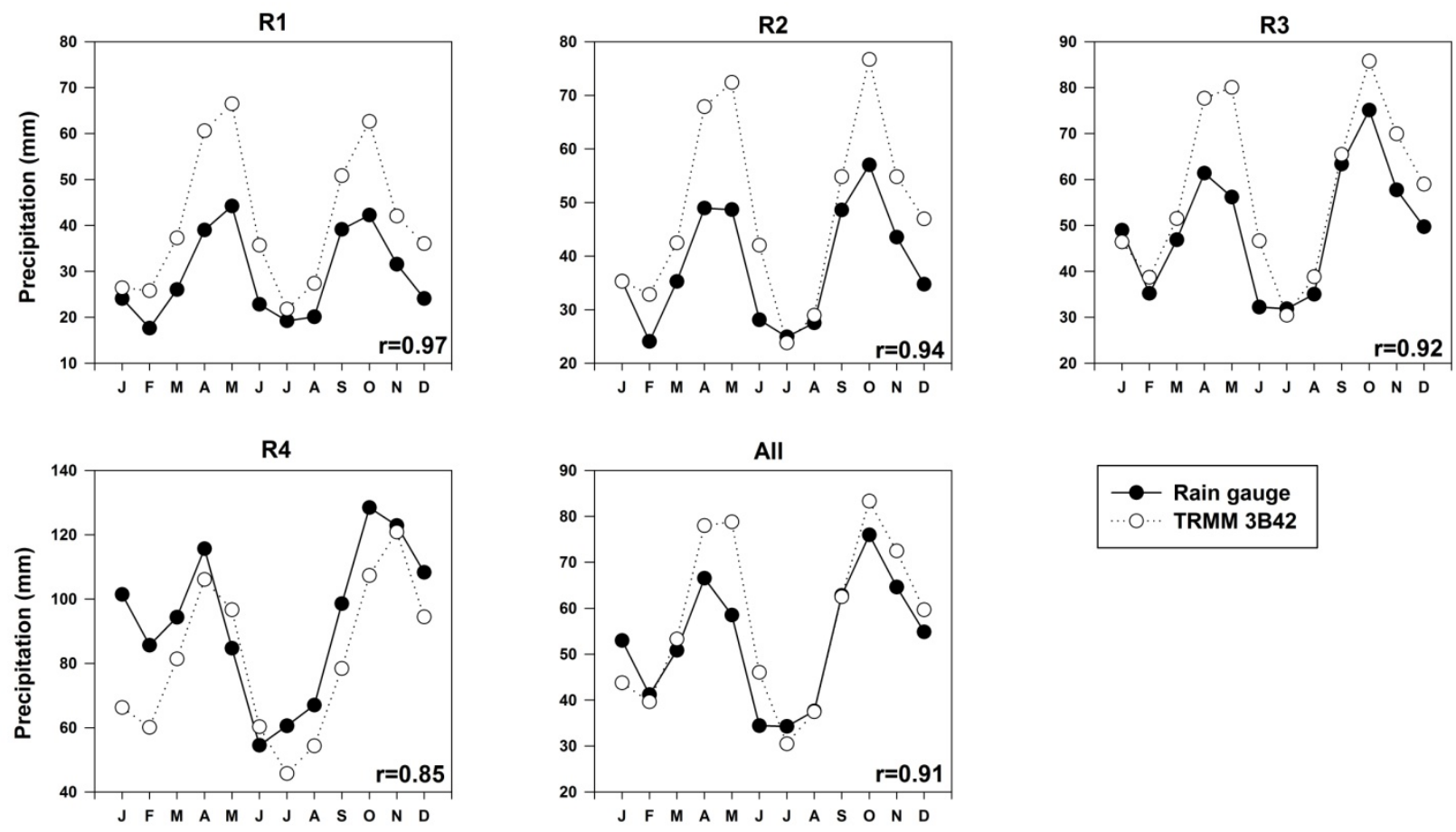

Figure 9: Mean annual cycle of precipitation derived from the TRMM $3 B 42$ versus rain gauge data. Pearson correlation coefficient is also provided for each region. 

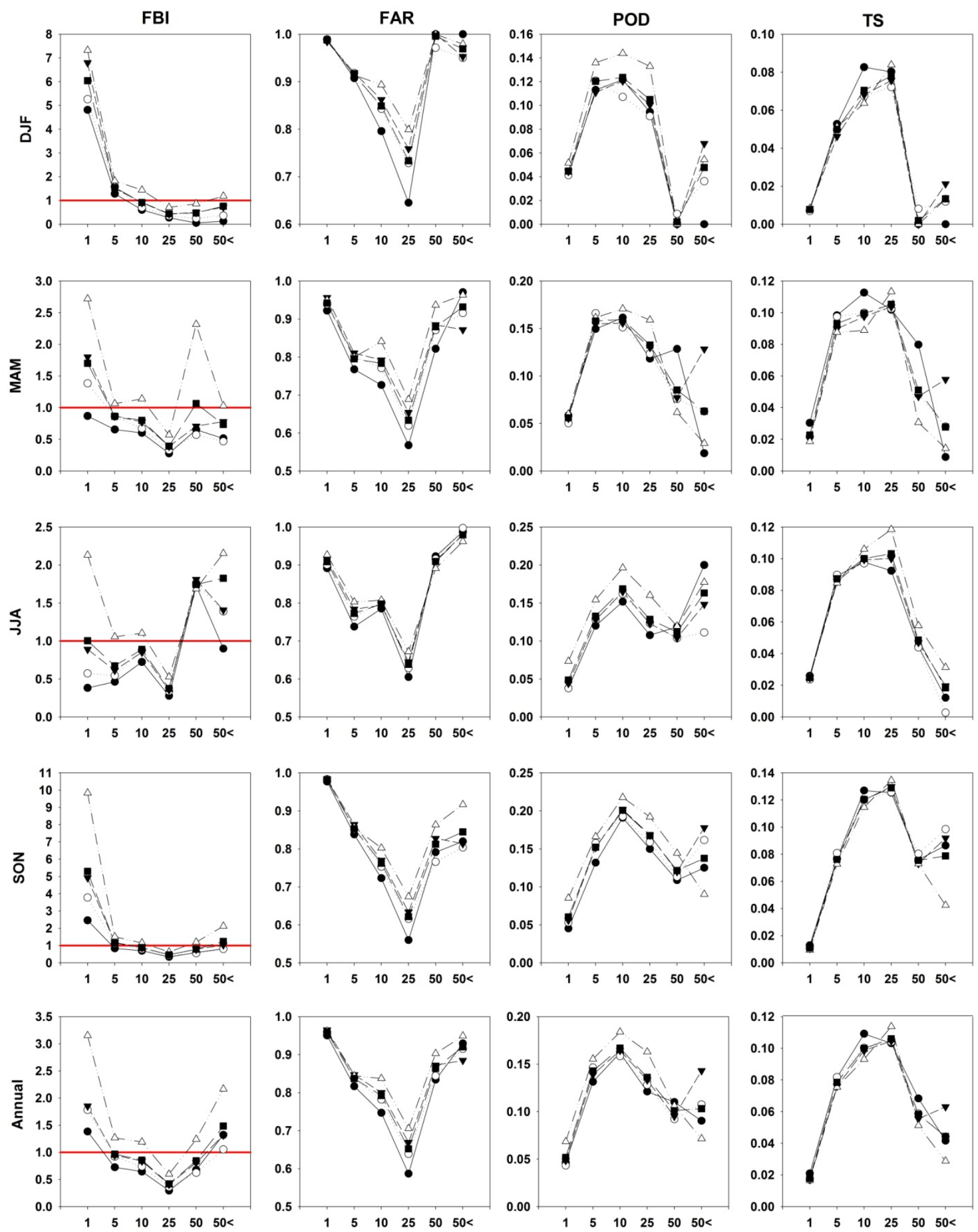

Precipitation threshold (mm/day)

Figure 10: Seasonal and annual results of the different skill metrics for different daily rainfall thresholds. All of these indicators are averaged for each sub-region as well as the whole domain. The red line of the FBI panels indicates a perfect skill. 

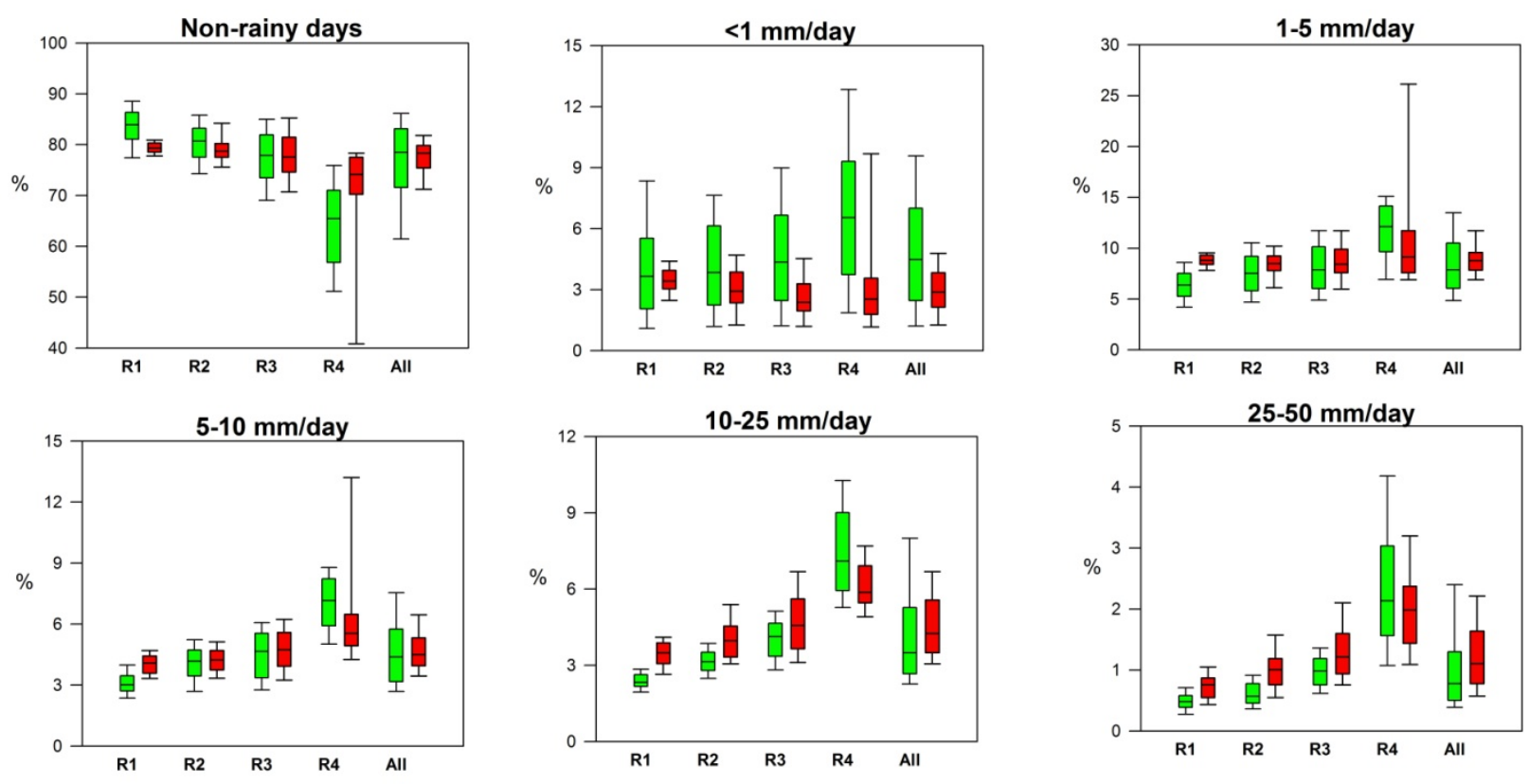

1166

1167

1168

1169

1170

1171

1172

1173

1174

1175

1176

1177

1178

1179

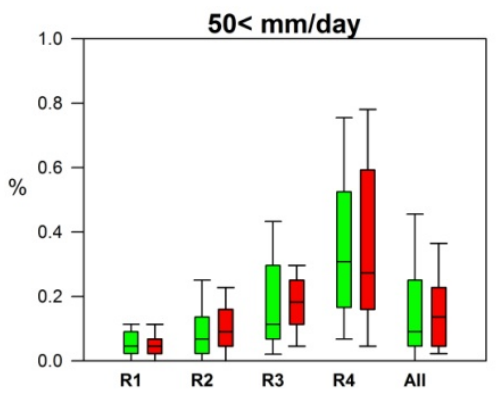

Figure 11: Relative contributions (\%) of the frequency of occurrence of days at different thresholds using gauge (green) and TRMM 3B42 (red) data. 

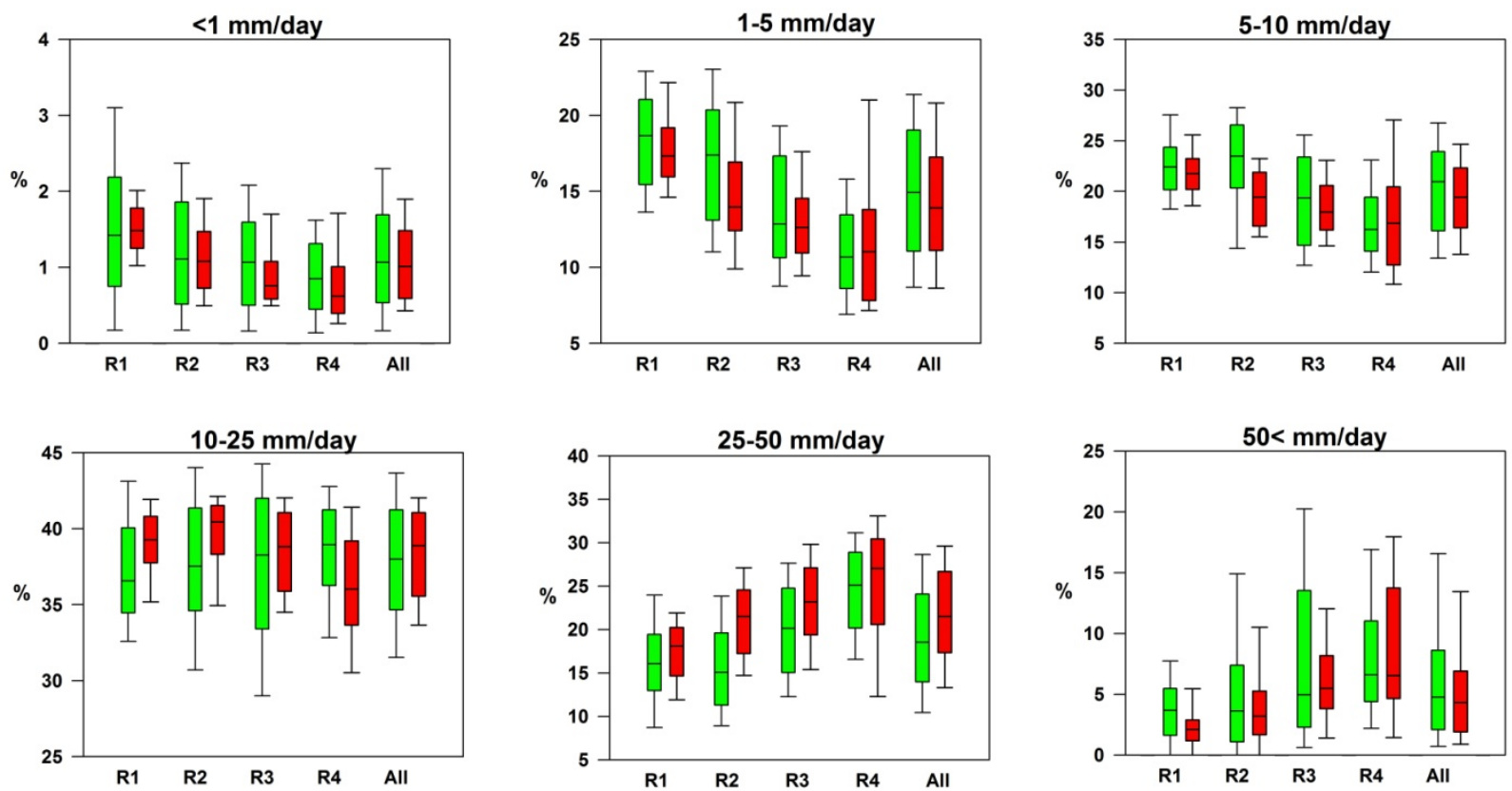

1189

1190

1191

1192

1193

1194

1195

1196

1197

1198

1199

1200

1201

1202

1203

1204

1205

1206

1207

1208

1209

1210

Figure 12: Relative contributions (\%) of daily precipitation to the total precipitation at different thresholds using gauge (green) and TRMM 3B42 (red) data. 